\title{
Reductive Cleavage of Secondary Sulfonamides: Converting Terminal Functional Groups into Versatile Synthetic Handles
}

Patrick Fier, Suhong Kim, Kevin M. Maloney

Submitted date: 01/10/2019 Posted date: 03/10/2019

Licence: CC BY-NC-ND 4.0

Citation information: Fier, Patrick; Kim, Suhong; Maloney, Kevin M. (2019): Reductive Cleavage of Secondary Sulfonamides: Converting Terminal Functional Groups into Versatile Synthetic Handles. ChemRxiv. Preprint.

Sulfonamides are pervasive in drugs and agrochemicals, yet are typically considered as terminal functional groups rather than synthetic handles. To enable the general late-stage functionalization of secondary sulfonamides, we have developed a mild and general method to reductively cleave the N-S bonds of sulfonamides to generate sulfinates and amines, components which can further react in-situ to access a variety of other medicinally relevant functional groups. The utility of this platform is highlighted by the selective manipulation of several complex bioactive molecules.

File list (2)

Secondary Sulfonamide Paper_ChemRxiv.pdf (379.52 KiB) view on ChemRxiv • download file 


\title{
Reductive Cleavage of Secondary Sulfonamides: Converting Terminal Functional Groups into Versatile Synthetic Handles
}

\author{
Patrick S. Fier,* Suhong Kim, and Kevin M. Maloney* \\ Department of Process Research and Development, Merck \& Co., Inc., Rahway, New Jersey 07065, United States
}

Supporting Information Placeholder

\begin{abstract}
Sulfonamides are pervasive in drugs and agrochemicals, yet are typically considered as terminal functional groups rather than synthetic handles. To enable the general latestage functionalization of secondary sulfonamides, we have developed a mild and general method to reductively cleave the $\mathrm{N}$ $\mathrm{S}$ bonds of sulfonamides to generate sulfinates and amines, components which can further react in-situ to access a variety of other medicinally relevant functional groups. The utility of this platform is highlighted by the selective manipulation of several complex bioactive molecules.
\end{abstract}

The ability to selectively modify single sites of complex molecules is a powerful and efficient tool in drug discovery, as single-point modifications can have profound impacts on biological and physicochemical properties. ${ }^{1}$ Given that sulfonamides and related bioisosteres are prevalent in medicines across all therapeutic areas, ${ }^{2}$ the development of methods for their selective manipulation could accelerate drug discovery. Yet, beyond simple $\mathrm{C}-\mathrm{N}$ bond forming reactions, secondary sulfonamides have been treated as terminal functional groups as there are no other methods for their late-stage modification. ${ }^{3}$

Sulfonamides are ubiquitous in drug design, in part because they are metabolically stable ${ }^{4}$ and easy to prepare from sulfonyl chlorides and amines. ${ }^{5}$ However, given that sulfonyl chlorides are highly reactive and not stable within typical complex molecules, sulfonamides are often formed early in a synthetic sequence and carried through with the sulfonamide moiety fixed. For example, the synthesis of a sulfonamide-containing drug candidate (Figure 1A) relied on a 6-step sequence following the installation of the aniline group. ${ }^{6}$ While such a sequence could be satisfactory to prepare a single target, it is not practical for typical structureactivity relationship studies in drug discovery. In addition, early installation of sulfonamides could restrict the types of functional groups present on the substituents of the sulfonamide, as the downstream chemistry could present incompatibilities. Thus, a general platform that enables late-stage functionalization of complex secondary sulfonamides under mild reaction conditions in a single reaction vessel would be particularly powerful in drug discovery programs (Fig. 1B). ${ }^{7}$

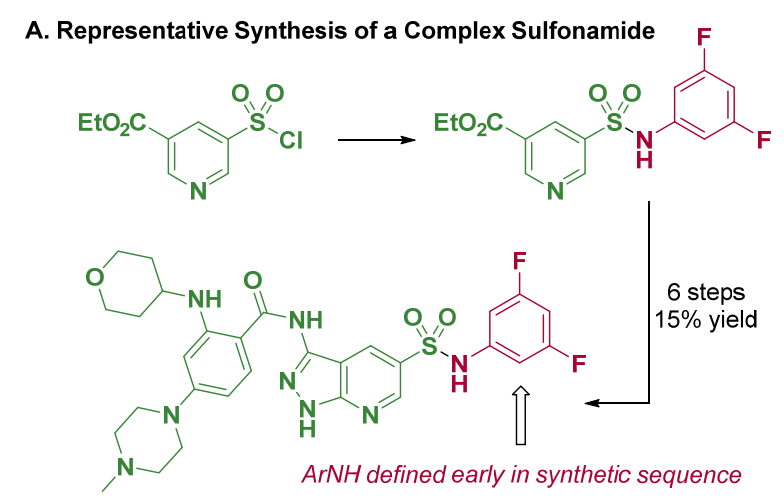

B. Novel Transformations of Interest to Drug Discovery (this work) Conversion of $\mathrm{SO}_{2}$ to $\mathrm{CO}$ Change identity of $R^{\prime}$ group

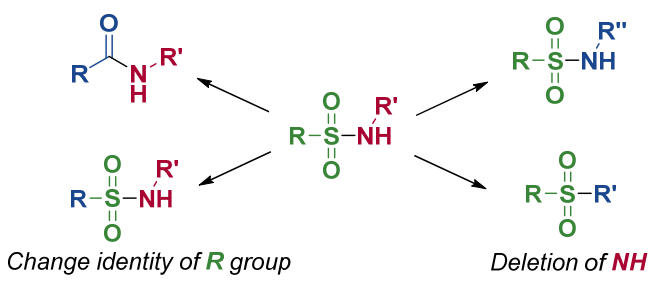

Unknown transformations for late-stage functionalization

Figure 1. Secondary Sulfonamides in Drug-Like Molecules

As part of a program to realize sulfonamides as points of diversification, we recently reported a general platform for the conversion of primary sulfonamides to a variety of other bioactive motifs through the in-situ generation of sulfinates (Figure 2A). ${ }^{8}$ While this method has already been adopted for late-stage functionalization, the reaction mechanism limits this chemistry to the diversification of primary sulfonamides. As primary and secondary sulfonamides are equally common across pharmaceuticals, we sought to develop a method that could enable a similar reductive cleavage of the $\mathrm{N}-\mathrm{S}$ bonds in secondary sulfonamides. However, secondary sulfonamides present additional challenges, most notably that across existing secondary sulfonamide drugs there is a similar number of compounds in which the amine-containing piece is complex (Figure 2B) ${ }^{9}$ and compounds in which the sulfonyl piece is complex (Figure 2C). ${ }^{10}$ Thus, we aimed to develop a method that enables the functionalization of either component of a secondary sulfonamide under mild conditions while tolerating functionality commonly found in drug-like molecules. 
A. Late-Stage Functionalization of Primary Sulfonamides (ref X)

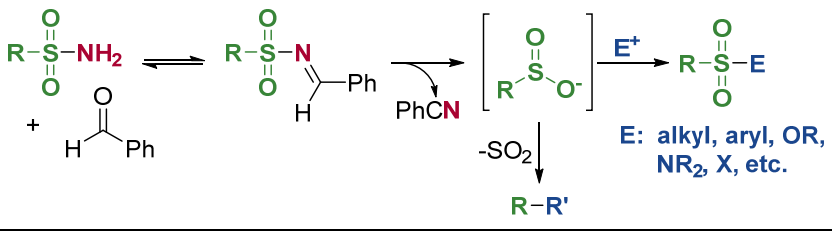

B. Secondary Sulfonamides with Complex Amino Group
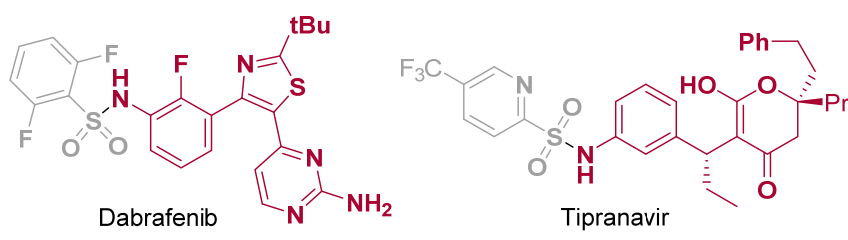

C. Secondary Sulfonamides with Complex Sulfonyl Components

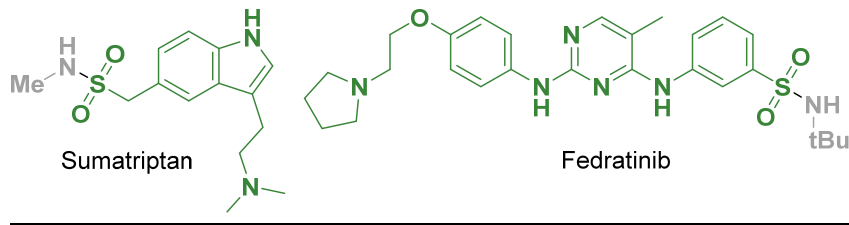

D. Concept for Secondary Sulfonamide Functionalization

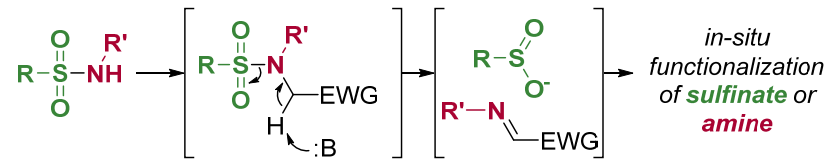

Chemoselective alkylation

Base-mediated elimination of sulfonamide

Figure 2. Late-Stage Functionalization of Sulfonamides: Inspiration and Strategy

In designing a method for the late-stage functionalization of secondary sulfonamides, we envisioned a reaction that would selectively functionalize secondary sulfonamides to generate an intermediate containing an acidic $\mathrm{C}-\mathrm{H}$ bond adjacent to nitrogen. This intermediate would then react under basic conditions to liberate a sulfinate anion while at the same time generating an imine (Figure 2D). Such a reaction manifold would enable subsequent functionalization of the sulfinate using well-established chemistry, or functionalization of the amine after imine cleavage.

Initially, we investigated reactions for the chemo-selective alkylation of secondary sulfonamides with alkyl halides containing electron-withdrawing groups that would promote the subsequent elimination step. However, the use of such alkyl halides resulted in complex mixtures when we tried to apply this approach to complex, drug-like molecules (Figure 3A). Next, approaches based on the Petasis reaction were explored as a chemoselective entry to access $N$-sulfonyl phenylglycine ester intermediates. ${ }^{11}$ While the Petasis reaction worked on simple substrates, the reaction was not general enough for a broadly useful platform in late-stage functionalization. Finally, we investigated reactions that would be chemoselective based on the acidity of the N-H bond of secondary sulfonamides. We found that Mitsunobu reactions of secondary sulfonamides with ethyl mandelate proceeded smoothly to form $\mathrm{N}$-sulfonyl phenylglycine ester intermediates. ${ }^{12}$ Unfortunately, the subsequent elimination was complicated due to the byproducts of the Mitsunobu Reaction. Therefore, to simplify the C-N bond forming step and avoid the hydrazine byproducts of the Mitsunobu reaction, the activated phosphonium intermediate was generated from ethyl benzoylformate and tris(dimethylamino)phosphine (Figure 3B). ${ }^{13}$

We found that secondary sulfonamides react rapidly and chemoselectively with the combination of ethyl benzoylformate and tris(dimethylamino)phosphine in THF at ambient temperature over 15-30 minutes to form $N$-sulfonyl phenylglycine ester interemediates. Although the phosphine reagent is moderately air and moisture sensitive, we carried out all reactions on the benchtop without any special precautions. For cleavage of the adducts, an exhaustive screen of bases revealed that reactions with $t$-butyl tetramethylguanidine (BTMG, Barton's base) ${ }^{14}$ resulted in clean fragmentation and concomitant generation of the desired sulfinate and imine products, both of which can be re-functionalized in-situ. The net transformation in this cleavage process is a two-electron reduction of the N-S bond driven by the oxidation of $\mathrm{P}(\mathrm{III})$ to $\mathrm{P}(\mathrm{V})$. The ethyl benzoylformate in these reactions acts as a redox shuttle, initially undergoing reduction followed by base-mediated oxidation.

A. Initial Attempts to Access $\mathbf{N}$-Alkyl Intermediates

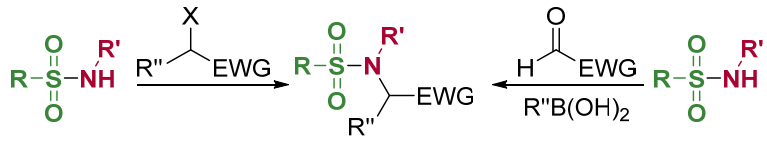

B. Development of Chemoselective Alkylation and $\mathrm{N}$-S Cleavage

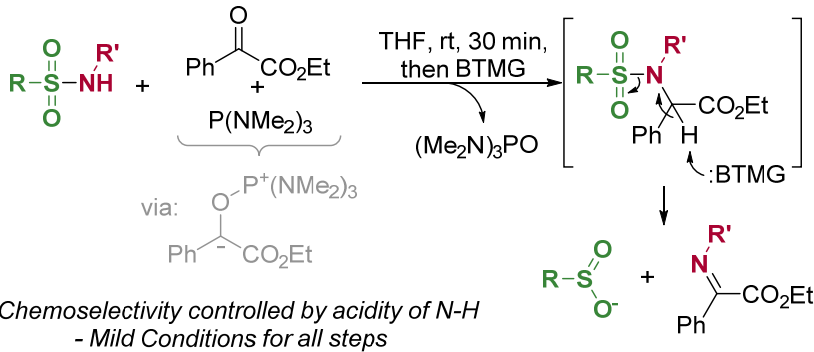

- Applicable towards late-stage diversification

Figure 3. The development of a general platform for N-alkylation and base-mediated N-S cleavage

With conditions in hand for the chemoselective N-S cleavage of secondary sulfonamides, we carried out an initial survey of the scope with respect to the electronic properties of the sulfonamide. Four sulfonamide substrates comprising the combinations of alkyl and aryl groups on $\mathrm{S}$ and $\mathrm{N}$ were subjected to the standard reaction conditions and the conversion was analyzed on an HPLC instrument (Scheme 1). Across the four sulfonamides, high conversion to the sulfinate and imine were observed. The imines generated in the reaction were stable to HPLC analysis, and the free amine could be revealed in quantitative yield within minutes through the addition of aqueous hydroxylamine to the crude reaction mixture.

Scheme 1. Initial survey of scope for $\mathrm{N}-\mathrm{S}$ cleavage with simple secondary sulfonamides

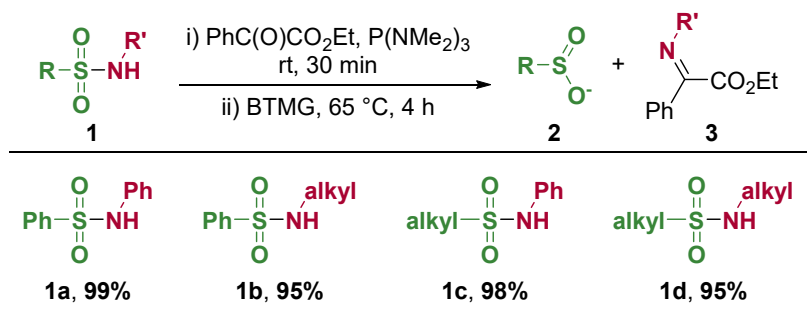

aPercent conversion of $\mathbf{1}$ to $\mathbf{2}+\mathbf{3}$ based on HPLC area percent at $210 \mathrm{~nm}$ for reactions carried out on $1.0 \mathrm{mmol}$ scale. Alkyl = $\mathrm{CH}_{2} \mathrm{CH}_{2} \mathrm{Ph}$. For experimental details, see the Supporting Information.

Having validated the methodology on simple substrates, we then applied this N-S cleavage concept towards late-stage diversification. First, we carried out reactions on drug-like 
compounds containing secondary sulfonamides in which the nitrogen component is complex. The standard conditions were applied to sulfonamides containing ketone, ester, triflate, halide, indole $\mathrm{N}-\mathrm{H}$, unprotected aminopyrimidine, secondary amide, and various heterocyclic functional groups. In all cases, the reductive cleavage process was chemoselective for reactions at secondary sulfonamides due to the acidity of the $\mathrm{N}-\mathrm{H}$ bonds. The imine generated in the reductive process was readily cleaved with aqueous hydroxylamine and the amine could be functionalized insitu. As shown in Scheme 2, this sequence allows for the facile interconversion of sulfonamides and the transformation of sulfonamides to amides.

Scheme 2. Late-Stage Modification of Secondary Sulfonamides Containing Complex Nitrogen Fragments

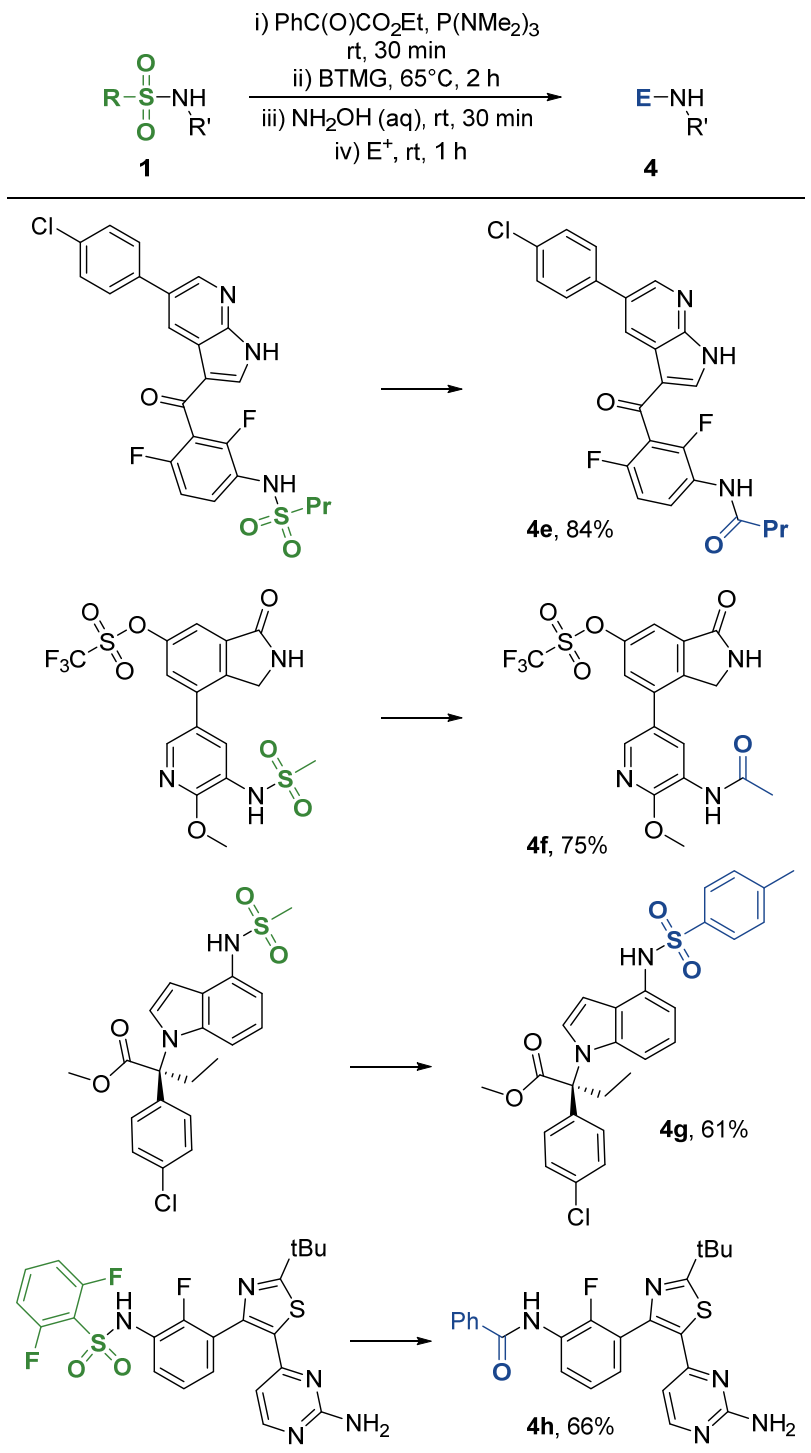

a Isolated yields shown for reactions carried out with $0.5 \mathrm{mmol}$ of sulfonamide substrate. For experimental details, see the Supporting Information.

Similar to the modification of the nitrogen component of secondary sulfonamides, this methodology was successfully applied to the late-stage functionalization of several secondary sulfonamides containing complex sulfonyl pieces. The resultant sulfinate species generated in-situ from the reductive cleavage process react with exogenous electrophiles to form a variety of $\mathrm{S}(\mathrm{VI})$ functional groups, such as sulfones, as shown in Scheme 3.
The mild conditions are highlighted by the site-selective modification of sulfonamides in the presence of free amines, secondary amides, cyano groups, halides, and diverse heterocyclic functional groups.

Scheme 3. Late-Stage Modification of Secondary Sulfonamides Containing Complex Sulfonyl Fragments
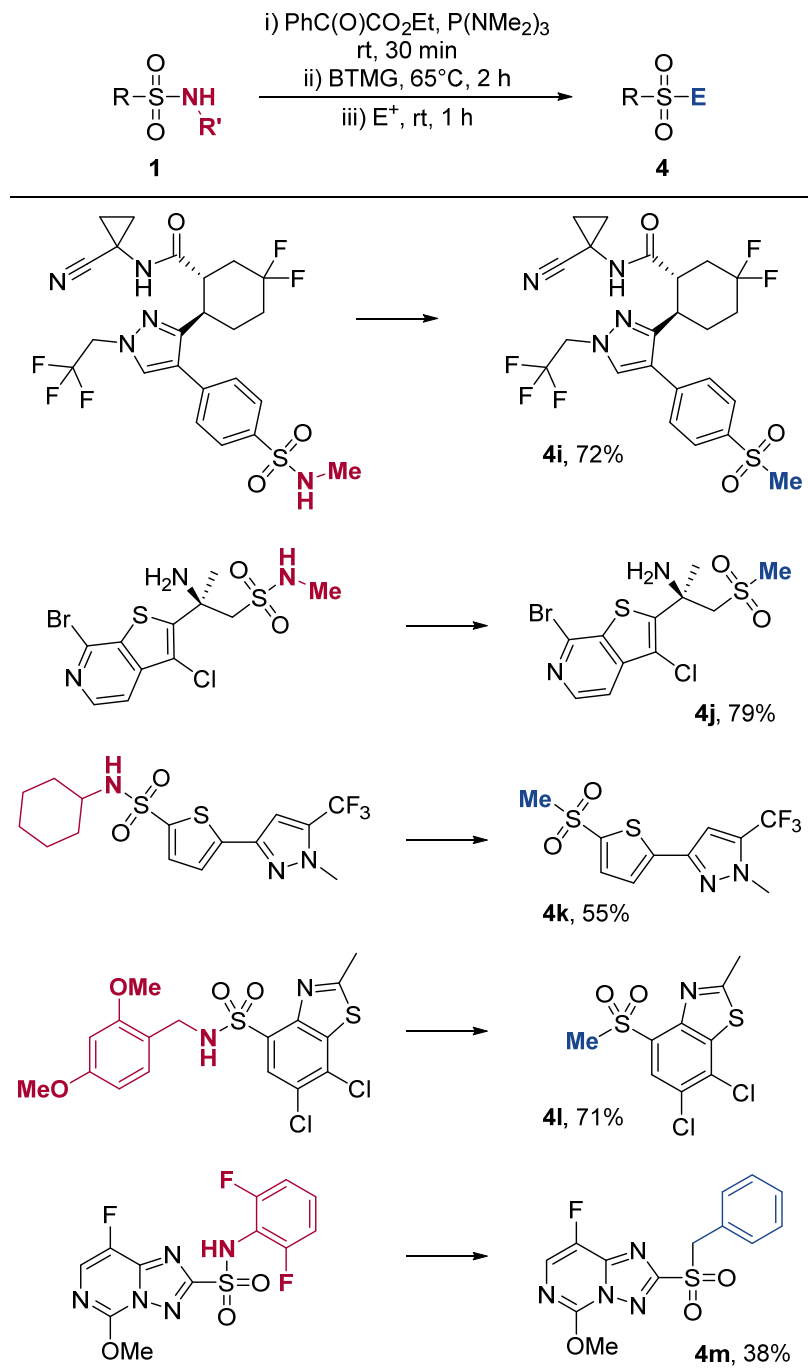

asslated yields shown for reactions carried out with $0.5 \mathrm{mmol}$ of sulfonamide substrate. For experimental details, see the Supporting Information.

Lastly, we demonstrated the application of this method towards metabolite and labeled compound synthesis, both integral facets of drug discovery and development. ${ }^{15}$ In the synthesis of metabolites or labeled compounds, the direct use of the drug molecule is generally preferred, as it is usually available within the organization and avoids long synthetic sequences. As depicted in Scheme 4, the complex $N$-methylsulfonamide was subjected to the reductive N-S cleavage, followed by treatment of the crude sulfinate mixture with either $\mathrm{NH}_{4} \mathrm{OH}$ and iodine to preapre the desmethylated metabolite, or $\mathrm{CD}_{3} \mathrm{NH}_{3} \mathrm{Cl}$ and iodine to prepare the $\mathrm{CD}_{3}$-labeled compound. The labeled compound was prepared in a one-pot process on 3-gram scale and led to net conversion of the $\mathrm{CH}_{3}$ group to a $\mathrm{CD}_{3}$ group. Notably, the methylamino group cleaved in the first step remained sequestered as an imine and did not interfere in the reactions to reform sulfonamides. 
Scheme 4. Late-Stage Metabolite Synthesis and Isotopic Labeling through N-S Cleavage and Reconstitution
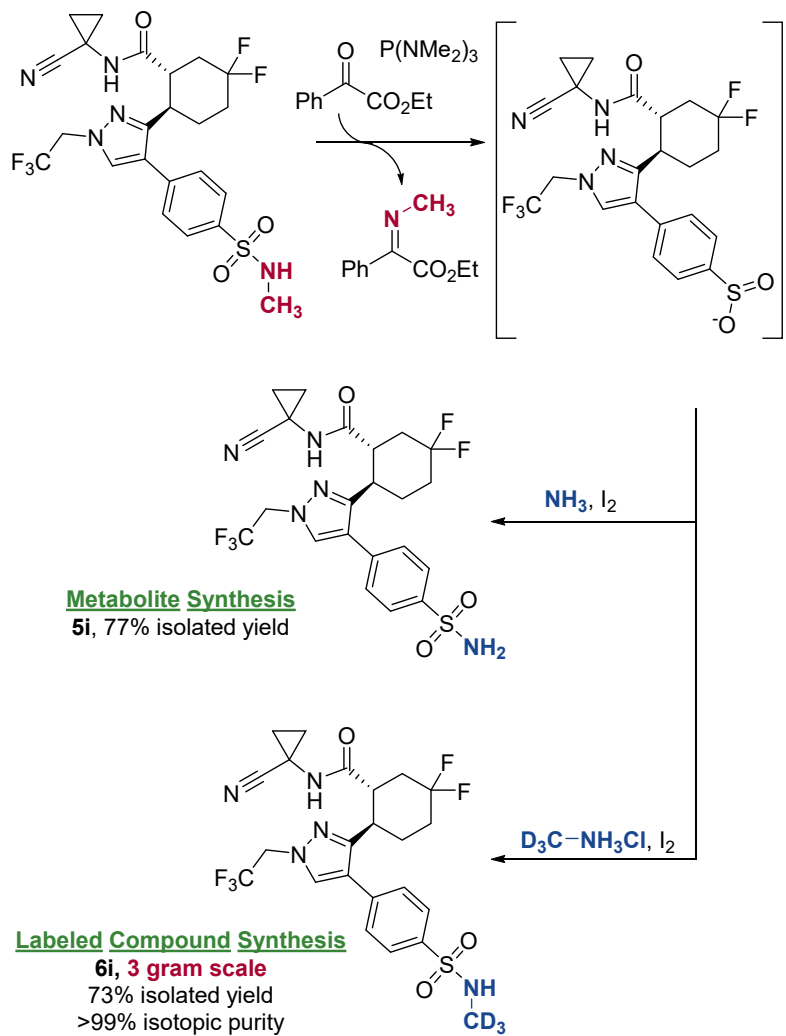

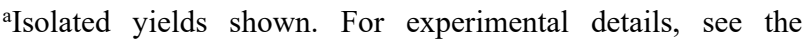
Supporting Information

In summary, we have developed a general platform for the latestage functionalization of secondary sulfonamides as part of our program on upgrading sulfonamides from terminal functional groups to synthetic handles. The exceptional functional group tolerance, use of simple reagents in air, and the ability to carry out unprecedented transformations on prevalent sulfonamide functional groups makes this a powerful tool for complex molecule functionalization.

\section{ASSOCIATED CONTENT}

\section{Supporting Information}

Experimental details and characterization data for new compounds. This material is available free of charge via the Internet at http://pubs.acs.org.

\section{AUTHOR INFORMATION}

\section{Corresponding Authors}

*E-mail: patrick.fier@merck.com

*E-mail: kevin_maloney@merck.com

\section{ACKNOWLEDGMENT}

We would like to thank our colleagues L. C. Campeau, Neil Strotman, Ben Sherry, and J. J. Yin for their helpful feedback. S.K. would like to thank the Merck internship program.

\section{REFERENCES}

1. (a) Li, J. J.; Corey, E. J. Drug Discovery. Practices, Processes, and Perspectives; Wiley, 2013. (b) Tishler, $M$. Molecular Modification in Modern Drug Research. In Molecular Modification in Drug Design; American
Chemical Society: New York, NY, 1963; Chapter 1. (c) Patani, G. A.; LaVoie, E. J. Bioisosterism: A Rational Approach in Drug Design. Chem. Rev. 1996, 96, 3147-3176.

2. (a) Lesch, J. E. The First Miracle Drugs: How the Sulfa Drugs Transformed Medicine; Oxford University Press, 2006. (b) Li, J. J.; Corey, E. J. Drug Discovery. Practices, Processes, and Perspectives; Wiley, 2013. (c) Smith, B. R.; Eastman, C. M.; Njardarson, J. T. Beyond C, H, O, and N! Analysis of the Elemental Composition of U.S. FDA Approved Drug Architectures. J. Med. Chem. 2014, 57, 9764. (d) Ilardi, E. A.; Vitaku, E.; Njardarson, J. T. Data-Mining for Sulfur and Fluorine: An Evaluation of Pharmaceuticals To Reveal Opportunities for Drug Design and Discovery. J. Med. Chem. 2014, 57, 2832. (e) Scott, K. A.; Njardarson, J. T. Analysis of US FDAApproved Drugs Containing Sulfur Atoms Top. Curr. Chem. (Z) $2018,376,376$

3. (a) Wuts, P. G. M Protection for the Amino Group. In Greene's Protective Groups in Organic Synthesis, 5th ed.; John Wiley \& Sons: Hoboken, NJ, 2014; Chapter 7. (b) Kocieński, P. J. Amino Proecting Groups. In Protecting Groups, 3rd ed.; Thieme: New York, NY, 2005; Chapter 8.

4. Masimirembwa, C. M.; Bredberg, U.; Andersson, T. B. Metabolic Stability for Drug Discovery and Development: Pharmacokinetic and Biochemical Challenges. Clin. Pharmacokinet. 2003, 42, 515-528.

5. For modern alternaive methods to prepare sulfonamides, see: (a) Caddick, S.; Wilden, J. D.; Judd, D. B. Direct Synthesis of Sulfonamides and Activated Sulfonate Esters from Sulfonic Acids. J. Am. Chem. Soc. 2004, 126, 1024. (b) DeBergh, J. R.; Niljianskul, N.; Buchwald, S. L. Synthesis of Aryl Sulfonamides via PalladiumCatalyzed Chlorosulfonylation of $\mathrm{Ar}$ ylboronic Acids. J. Am. Chem. Soc. 2013, 135, 10638. (c) Shavnya, A.; Coffey, S. B.; Smith, A. C.; Mascitti, V. Palladium-Catalyzed Sulfination of Aryl and Heteroaryl Halides: Direct Access to Sulfones and Sulfonamides. Org. Lett. 2013, 15, 6226. (d) Johnson, M. W.; Bagley, S. W.; Mankad, N. P.; Bergman, R. G.; Mascitti, V.; Toste, F. D. Application of Fundamental Organometallic Chemistry to the Development of a Gold-Catalyzed Synthesis of Sulfinate Derivatives. Angew. Chem., Int. Ed. 2014, 53, 4404. (e) Tsai, A. S.; Curto, J. M.; Rocke, B. N.; Dechert-Schmitt, A.- M R.; Ingle, G. K.; Mascitti, V. One-Step Synthesis of Sulfonamides from NTosylhydrazones. Org. Lett. 2016, 18, 508. (f) Deeming, A. S.; Russell, C. J.; Willis, M. C. Palladium(II)-Catalyzed Synthesis of Sulfinates from Boronic Acids and DABSO: A Redox-Neutral, Phosphine-Free Transformation. Angew. Chem., Int. Ed. 2016, 55, 747. (g) Chen, Y.; Murray, P. R. D.; Davies, A. T.; Willis, M. C. Direct Copper-Catalyzed Three-Component Synthesis of Sulfonamides. J. Am. Chem. Soc. 2018, 140, 8781. (h) Laudadio, G.; Barmpoutsis, E.; Schotten, C.; Struik, L.; Govaerts, S.; Browne, D. L.; Noël, T. J. Am. Chem. Soc. 2019, 141, 5664.

6. Patents WO2012/101239, US2013/85144, WO2014/16434

7. Cernak, T.; Dykstra, K. D.; Tyagarajan, S.; Vachal, P.; Krska, S. W. The medicinal chemist's toolbox for late stage functionalization of druglike molecules. Chem. Soc. Rev. 2016, 45, 546-576.

8. a) Fier, P. S.; Maloney, K. M. NHC-Catalyzed Deamination of Primary Sulfonamides: A Platform for Late-Stage Functionalization. $J$. Am. Chem. Soc. 2019, 141, 1441-1445. See also b) Gauthier, D. R., Jr.; Yoshikawa, N. A. General, One-Pot Method for the Synthesis of Sulfinic Acids from Methyl Sulfones. Org. Lett. 2016, 18, 5994.

9. (a) Ballantyne, A. D.; Garnock-Jones, K. P. Dabrafenib: First Global Approval. Drugs 2013, 73, 1367-1376. (b) Flexner, C.; Bate, G.; Kirkpatrick, P. Tipranavir. Nature Rev. Drug Discov. 2005, 4, 955-956.

10. (a) Perry, C. M.; Markham, A. Sumatriptan: An Updated Review of its Use in Migraine. Drugs 1998, 55, 889-922. (b) Wernig, G.; Kharas, M. G.; Okabe, R.; Moore, S. A.; Leeman, D. S.; Cullen, D. E.; Gozo, M.; McDowell, E. P.; Levine, R. L.; Doukas, J.; Mak, C. C.; Noronha, G.; Martin, M.; Ko, Y. D.; Lee, B. H.; Soll, R. M.; Tefferi, A.; Hood, J. D.; Gilliland, D. G. Cancer Cell 2008, 13, 311.

11. (a) Beisel, T.; Manolikakes, G. Palladium-Catalyzed Enantioselective Three-Component Synthesis of $\alpha$-Substituted Amines. Org. Lett. 2015 17, 3162-3165. (b) Beisel, T.; Diehl, A. M.; Manolikakes, G. PalladiumCatalyzed Enantioselective Three-Component Synthesis of $\alpha$-Arylglycines. Org. Lett. 2016, 18, 4116-4119 (c) Diehl, A. M.; Ouadoudi, O.; Andreadou, E.; Manolikakes, G. Sulfonamides as Amine Component in the Petasis-Borono Mannich Reaction: A Concise Synthesis of $\alpha$-Aryl- and $\alpha$-Alkenylglycine Derivatives. Synthesis 2018, 50, 3936-3946.

12. Wisniewski, K.; Koldziejczyk, A. S.; Falkiewicz, B. Applications of the Mitsunobu Reaction in Peptide Chemistry. J. Pept. Sci. 1998, 4, 1-14.

13. Zhao, W.; Radosevich, A. T. Phosphorus(III)-Mediated Reductive Condensation of $\alpha$-Keto Esters and Protic Pronucleophiles. Org. Synth. 2015, 92, 267-276. 
14. Barton, D. H. R.; Elliott, J. D.; Gero, S. D. Synthesis and properties of a series of sterically hindered guanidine bases J. Chem. Soc., Perkin Trans. 1 1982, 2085-2090.

15. Dean, D. C.; Filer, C. N.; McCarthy, K. E. Synthesis and Applications of Isotopically Labelled Compounds; Wiley, 2004.

Insert Table of Contents artwork here 
Supporting Information for:

Reductive Cleavage of Secondary Sulfonamides: Converting Terminal Functional Groups into Versatile Synthetic Handles

Patrick S. Fier, ${ }^{*}$ Suhong Kim, and Kevin M. Maloney* 


\section{General experimental details}

Reagents and common substrates were purchased from commercial suppliers and used as received. Non-commercially available substrates were procured from Merck's building block collection and used as received. Anhydrous THF was purchased from Sigma Aldrich (Sure/Seal ${ }^{\mathrm{TM}}$ ) and used as received. All reactions were setup on the benchtop in screw cap vials without any special precautions towards air or moisture. NMR spectra were obtained in DMSO- $d_{6}$ containing tetramethylsilane, chemical shifts are reported in ppm and referenced to residual solvent peaks.

\section{General procedures for the conversion of secondary sulfonamides to other functional groups}

To a screw-cap vial was added sulfonamide (1, 1.0 equiv), anhydrous THF ( $2.5 \mathrm{~mL}$ per mmol of 1), ethyl benzoylformate (1.1 equiv), and tris(dimethylamino)phosphine (1.2 equiv). Upon addition of tris(dimethylamino)phosphine a mild exotherm occurs which quickly subsides, care should be taken for reactions carried out on large scale. The reaction mixture is aged at ambient temperature for 30 minutes, during which time the secondary sulfonamide is converted to the $\mathrm{N}$-sulfonyl phenylglycine intermediate. Next, BTMG (1.25 equiv) is added, and the resulting mixture is heated at $65^{\circ} \mathrm{C}$ for $4 \mathrm{~h}$ to induce the elimination/fragmentation reaction. The rate of the elimination/fragmentation reaction varies with each substrate, with some reacting at lower temperature or in shorter reaction times, but no deleterious effects were observed when all reactions were aged at $65^{\circ} \mathrm{C}$ for the standard $4 \mathrm{~h}$ reaction time.

For cases where assay yields of the sulfinate salt and imine were determined (Scheme 1), the entire reaction mixture was diluted with $3: 1 \mathrm{MeCN}$ : water and the resulting solution was analyzed on an UPLC instrument. The approximate amount of the starting sulfonamide and product sulfinate and imine were determined by the area percent at $210 \mathrm{~nm}$ wavelength detection.

For cases where the nitrogen component of the sulfonamide was converted to other functional groups (Scheme 2), the reaction mixture from the N-S cleavage step was cooled to room temperature and treated with aqueous hydroxylamine (2.0 equiv relative to the starting sulfonamide). The resulting mixture was aged at room temperature for $30 \mathrm{~min}$ to ensure full conversion of the imine to the free amine. After complete conversion to the free amine, the electrophile (3.0 equiv) and pyridine (3.0 equiv) were added at once, and the resulting mixture was aged at room temperature for $1 \mathrm{~h}$. After complete conversion of the amine, the reaction mixture was concentrated to dryness and the crude residue was purified by silica gel chromatography.

For cases where the sulfinate was converted to a sulfone (Scheme 3), the reaction mixture from the N-S cleavage step was cooled to room temperature and treated with the alkyl electrophile (iodomethane or benzyl bromide, 2.0 equiv relative to the starting sulfonamide). The resulting mixture was aged at room temperature for $1 \mathrm{~h}$ to ensure full conversion. After complete conversion of the sulfinate, the reaction mixture was concentrated to dryness and the crude residue was purified by silica gel chromatography. 

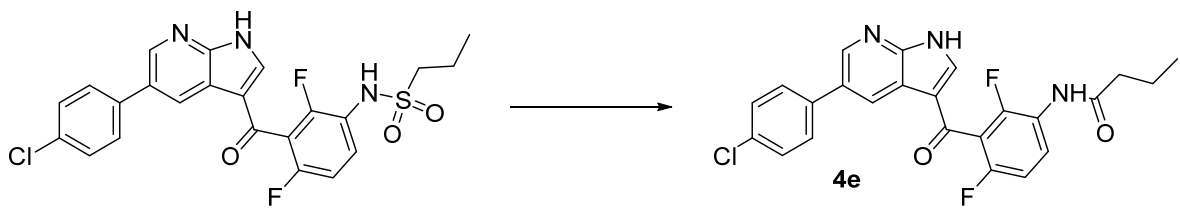

$\mathrm{N}$-(3-(5-(4-chlorophenyl)-1H-pyrrolo[2,3-

b]pyridine-3-carbonyl)-2,4-

difluorophenyl)butyramide Exact Mass: 453.11

\section{N-(3-(5-(4-chlorophenyl)-1H-pyrrolo[2,3-b]pyridine-3-carbonyl)-2,4-difluorophenyl)butyramide (4e)}

To a screw-cap vial was added sulfonamide (1e, $0.50 \mathrm{mmol}, 1.0$ equiv), anhydrous THF (1.25 mL), ethyl benzoylformate $(0.55 \mathrm{mmol}, 1.1$ equiv), and tris(dimethylamino)phosphine (0.6 mmol, 1.2 equiv). The reaction mixture is aged at ambient temperature for 30 minutes, during which time the secondary sulfonamide is converted to the $\mathrm{N}$-sulfonyl phenylglycine intermediate. Next, BTMG $(0.625 \mathrm{mmol}, 1.25$ equiv) is added, and the resulting mixture is heated at $65{ }^{\circ} \mathrm{C}$ for $4 \mathrm{~h}$ to induce the elimination/fragmentation reaction. The reaction mixture from the $\mathrm{N}-\mathrm{S}$ cleavage step was cooled to room temperature and treated with aqueous hydroxylamine $(1.0 \mathrm{mmol}, 2.0$ equiv relative to the starting sulfonamide). The resulting mixture was aged at room temperature for $30 \mathrm{~min}$ to ensure full conversion of the imine to the free amine. After complete conversion to the free amine, butyrl chloride $(1.5 \mathrm{mmol}, 3.0$ equiv) and pyridine (1.5 mmol, 3.0 equiv) were added at once, and the resulting mixture was aged at room temperature for $1 \mathrm{~h}$. After complete conversion of the amine, the reaction mixture was concentrated to dryness and the crude residue was purified by silica gel chromatography eluting with $0-10 \% \mathrm{MeOH}$ in DCM to afford $4 \mathrm{e}$ as a white solid in $84 \%$ yield.

${ }^{1} \mathrm{H}$ NMR $\left(500 \mathrm{MHz}, \mathrm{DMSO}-d_{6}\right) \delta 13.12(\mathrm{~s}, 1 \mathrm{H}), 9.89(\mathrm{~s}, 1 \mathrm{H}), 8.70(\mathrm{~d}, J=2.2 \mathrm{~Hz}, 1 \mathrm{H}), 8.64(\mathrm{~s}, 1 \mathrm{H}), 8.16(\mathrm{~s}$, $1 \mathrm{H}), 7.95(\mathrm{q}, J=8.7 \mathrm{~Hz}, 1 \mathrm{H}), 7.80(\mathrm{~d}, J=8.5 \mathrm{~Hz}, 2 \mathrm{H}), 7.59-7.54(\mathrm{~m}, 2 \mathrm{H}), 7.23(\mathrm{t}, J=8.7 \mathrm{~Hz}, 1 \mathrm{H}), 2.36$ $(\mathrm{t}, J=7.3 \mathrm{~Hz}, 2 \mathrm{H}), 1.61(\mathrm{~h}, J=7.3 \mathrm{~Hz}, 2 \mathrm{H}), 0.91(\mathrm{t}, J=7.4 \mathrm{~Hz}, 3 \mathrm{H})$.

${ }^{13} \mathrm{C}$ NMR $(126 \mathrm{MHz}$, DMSO-d6) $\delta 180.94,171.64,148.92,143.87,138.68,137.04,132.47,130.19$, 129.00 (d, $J=17.8 \mathrm{~Hz}$ ), 127.07, 123.27, 117.49, 115.65, 111.57 (d, $J=25.7 \mathrm{~Hz}), 37.49,18.51,13.51$. Note: Not all ${ }^{13} \mathrm{C}$ resonances could be unambiguously assigned due to the extremely low solubility of $4 \mathbf{e}$ in all solvents, including DMSO- $d_{6}$.

ESI MS: $454.28(\mathrm{M}+\mathrm{H})$ 

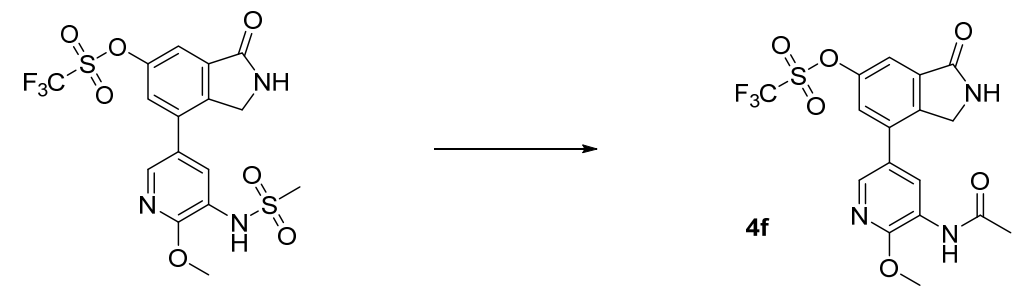

7-(5-acetamido-6-methoxypyridin-3-yl)-3oxoisoindolin-5-yl trifluoromethanesulfonate

Exact Mass: 445.06

\section{7-(5-acetamido-6-methoxypyridin-3-yl)-3-oxoisoindolin-5-yl trifluoromethanesulfonate (4f)}

To a screw-cap vial was added sulfonamide (1f, $0.50 \mathrm{mmol}, 1.0$ equiv), anhydrous THF (1.25 mL), ethyl benzoylformate $(0.55 \mathrm{mmol}, 1.1$ equiv), and tris(dimethylamino)phosphine (0.6 mmol, 1.2 equiv). The reaction mixture is aged at ambient temperature for 30 minutes, during which time the secondary sulfonamide is converted to the $\mathrm{N}$-sulfonyl phenylglycine intermediate. Next, BTMG $(0.625 \mathrm{mmol}, 1.25$ equiv) is added, and the resulting mixture is heated at $65{ }^{\circ} \mathrm{C}$ for $4 \mathrm{~h}$ to induce the elimination/fragmentation reaction. The reaction mixture from the $\mathrm{N}-\mathrm{S}$ cleavage step was cooled to room temperature and treated with aqueous hydroxylamine $(1.0 \mathrm{mmol}, 2.0$ equiv relative to the starting sulfonamide). The resulting mixture was aged at room temperature for $30 \mathrm{~min}$ to ensure full conversion of the imine to the free amine. After complete conversion to the free amine, acetyl chloride $(1.5 \mathrm{mmol}, 3.0$ equiv) and pyridine (1.5 mmol, 3.0 equiv) were added at once, and the resulting mixture was aged at room temperature for $1 \mathrm{~h}$. After complete conversion of the amine, the reaction mixture was concentrated to dryness and the crude residue was purified by silica gel chromatography eluting with $0-10 \% \mathrm{MeOH}$ in DCM to afford $\mathbf{4 f}$ as a white solid in $75 \%$ yield. The yield was corrected for a small amount of DCM that remained with the product even after a prolonged time under vacuum.

${ }^{1} \mathrm{H}$ NMR (500 MHz, DMSO-d6) $\delta 9.59(\mathrm{~s}, 1 \mathrm{H}), 9.01(\mathrm{~s}, 1 \mathrm{H}), 8.62-8.54(\mathrm{~m}, 1 \mathrm{H}), 8.20(\mathrm{~d}, J=2.3 \mathrm{~Hz}, 1 \mathrm{H})$, $7.83(\mathrm{~d}, J=2.3 \mathrm{~Hz}, 1 \mathrm{H}), 7.74(\mathrm{~d}, J=2.3 \mathrm{~Hz}, 1 \mathrm{H}), 4.57(\mathrm{~s}, 2 \mathrm{H}), 4.01(\mathrm{~s}, 3 \mathrm{H}), 2.14(\mathrm{~s}, 3 \mathrm{H})$.

${ }^{13} \mathrm{C}$ NMR $\left(126 \mathrm{MHz}\right.$, DMSO- $\left.d_{6}\right) \delta 169.54,167.85,154.15,149.48,141.83,139.60,136.22,135.81$, $128.36,125.43,123.64,122.55,119.56,117.01,114.66,53.77,44.92,23.78$. Note: The quartet for the $\mathrm{CF}_{3}$ carbon of the triflate group overlaps with other resonances.

ESI MS: $446.23(\mathrm{M}+\mathrm{H})$ 

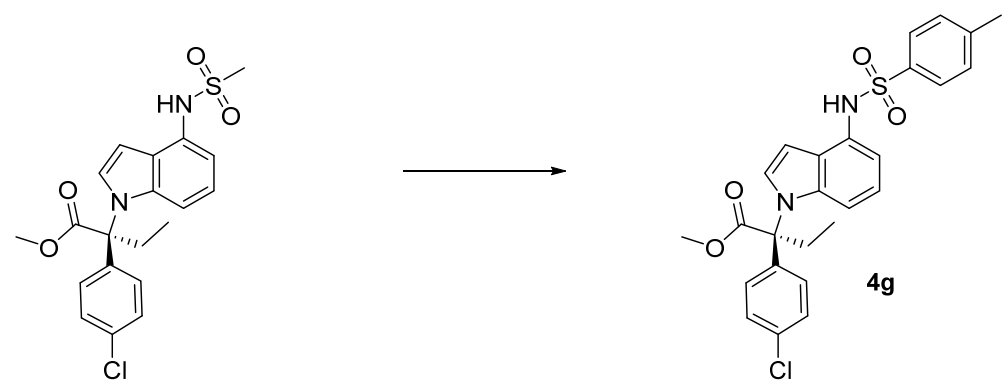

methyl (S)-2-(4-chlorophenyl)-2-(4-((4-

methylphenyl)sulfonamido)-1H-indol-1-yl)butanoate

Exact Mass: 496.12

methyl (S)-2-(4-chlorophenyl)-2-(4-((4-methylphenyl)sulfonamido)-1H-indol-1-yl)butanoate (4g)

To a screw-cap vial was added sulfonamide $(\mathbf{1 g}, 0.50 \mathrm{mmol}, 1.0$ equiv), anhydrous THF (1.25 $\mathrm{mL})$, ethyl benzoylformate $(0.55 \mathrm{mmol}, 1.1$ equiv), and tris(dimethylamino)phosphine (0.6 mmol, 1.2 equiv). The reaction mixture is aged at ambient temperature for 30 minutes, during which time the secondary sulfonamide is converted to the $\mathrm{N}$-sulfonyl phenylglycine intermediate. Next, BTMG $(0.625 \mathrm{mmol}, 1.25$ equiv) is added, and the resulting mixture is heated at $65{ }^{\circ} \mathrm{C}$ for $4 \mathrm{~h}$ to induce the elimination/fragmentation reaction. The reaction mixture from the $\mathrm{N}$-S cleavage step was cooled to room temperature and treated with aqueous hydroxylamine $(1.0 \mathrm{mmol}, 2.0$ equiv relative to the starting sulfonamide). The resulting mixture was aged at room temperature for $30 \mathrm{~min}$ to ensure full conversion of the imine to the free amine. After complete conversion to the free amine, p-toluenesulfonyl chloride (1.5 mmol, 3.0 equiv) and pyridine ( $1.5 \mathrm{mmol}, 3.0$ equiv) were added at once, and the resulting mixture was aged at room temperature for $1 \mathrm{~h}$. After complete conversion of the amine, the reaction mixture was concentrated to dryness and the crude residue was purified by silica gel chromatography eluting with 0 $10 \% \mathrm{MeOH}$ in DCM to afford $\mathbf{4 g}$ as a pale yellow oil in $61 \%$ yield.

ESI MS: $497.30(\mathrm{M}+\mathrm{H})$ 

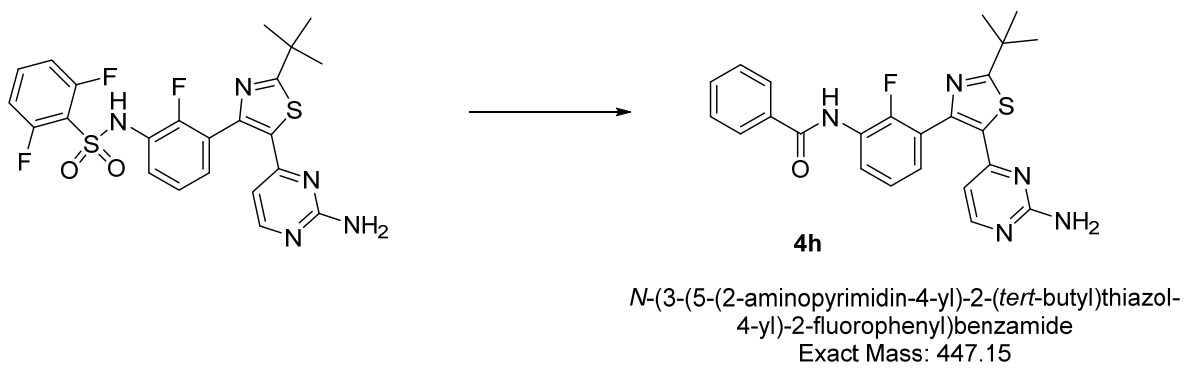

\section{N-(3-(5-(2-aminopyrimidin-4-yl)-2-(tert-butyl)thiazol-4-yl)-2-fluorophenyl)benzamide (4h)}

To a screw-cap vial was added sulfonamide ( $1 \mathrm{~h}, 0.50 \mathrm{mmol}, 1.0$ equiv), anhydrous THF (1.25 $\mathrm{mL})$, ethyl benzoylformate $(0.55 \mathrm{mmol}, 1.1$ equiv), and tris(dimethylamino)phosphine (0.6 mmol, 1.2 equiv). The reaction mixture is aged at ambient temperature for 30 minutes, during which time the secondary sulfonamide is converted to the $\mathrm{N}$-sulfonyl phenylglycine intermediate. Next, BTMG $(0.625 \mathrm{mmol}, 1.25$ equiv) is added, and the resulting mixture is heated at $65{ }^{\circ} \mathrm{C}$ for $4 \mathrm{~h}$ to induce the elimination/fragmentation reaction. The reaction mixture from the $\mathrm{N}-\mathrm{S}$ cleavage step was cooled to room temperature and treated with aqueous hydroxylamine $(1.0 \mathrm{mmol}, 2.0$ equiv relative to the starting sulfonamide). The resulting mixture was aged at room temperature for $30 \mathrm{~min}$ to ensure full conversion of the imine to the free amine. After complete conversion to the free amine, benzoyl chloride $(1.5 \mathrm{mmol}, 3.0$ equiv) and pyridine (1.5 mmol, 3.0 equiv) were added at once, and the resulting mixture was aged at room temperature for $1 \mathrm{~h}$. After complete conversion of the amine, the reaction mixture was concentrated to dryness and the crude residue was purified by silica gel chromatography eluting with $0-100 \%$ EtOAc in hexanes to afford $\mathbf{4 h}$ as a colorless oil in $66 \%$ yield. The yield was corrected for a small amount of EtOAc that remained with the product even after a prolonged time under vacuum.

${ }^{1} \mathrm{H}$ NMR (500 MHz, DMSO-d6) $\delta 10.20(\mathrm{~s}, 1 \mathrm{H}), 8.09$ (d, $\left.J=5.2 \mathrm{~Hz}, 1 \mathrm{H}\right), 7.98(\mathrm{~d}, J=7.7 \mathrm{~Hz}, 2 \mathrm{H}), 7.76$ (td, $J=7.4,1.6 \mathrm{~Hz}, 1 \mathrm{H}), 7.60(\mathrm{t}, J=7.3 \mathrm{~Hz}, 1 \mathrm{H}), 7.52(\mathrm{t}, J=7.7 \mathrm{~Hz}, 2 \mathrm{H}), 7.45-7.33(\mathrm{~m}, 3 \mathrm{H}), 6.73(\mathrm{~s}, 2 \mathrm{H})$, $6.18(\mathrm{~d}, J=5.2 \mathrm{~Hz}, 1 \mathrm{H}), 1.44(\mathrm{~s}, 9 \mathrm{H})$.

${ }^{13} \mathrm{C}$ NMR (126 MHz, DMSO-d $) \delta 181.30,170.08,165.56,163.36,158.87,157.50,152.90$ (d, $J=250.1$ $\mathrm{Hz}$ ), 145.83, 134.25, 133.80, 131.87, 129.26, 128.43, 128.23, 127.79, 126.85, 126.48 (d, $J=12.6 \mathrm{~Hz}$ ), 124.32 (d, $J=4.0 \mathrm{~Hz}), 123.88$ (d, $J=14.4 \mathrm{~Hz}), 105.44,37.62,30.35$.

ESI MS: $448.32(\mathrm{M}+\mathrm{H})$ 

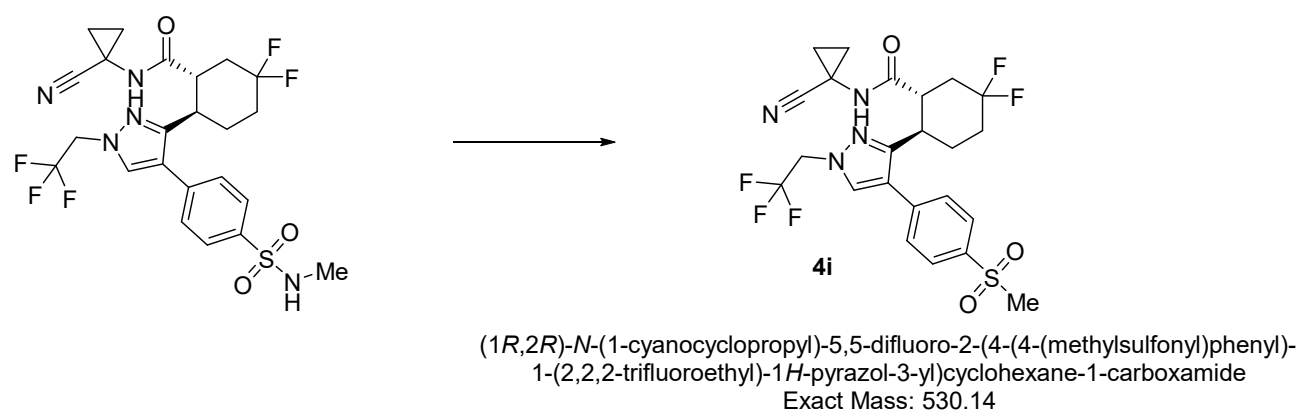

(1R,2R)-N-(1-cyanocyclopropyl)-5,5-difluoro-2-(4-(4-(methylsulfonyl)phenyl)-1-(2,2,2trifluoroethyl)-1H-pyrazol-3-yl)cyclohexane-1-carboxamide (4i)

To a screw-cap vial was added sulfonamide (1i, $0.50 \mathrm{mmol}, 1.0$ equiv), anhydrous THF (1.25 mL), ethyl benzoylformate $(0.55 \mathrm{mmol}, 1.1$ equiv), and tris(dimethylamino)phosphine (0.6 mmol, 1.2 equiv). The reaction mixture is aged at ambient temperature for 30 minutes, during which time the secondary sulfonamide is converted to the $\mathrm{N}$-sulfonyl phenylglycine intermediate. Next, BTMG $(0.625 \mathrm{mmol}, 1.25$ equiv) is added, and the resulting mixture is heated at $65{ }^{\circ} \mathrm{C}$ for $4 \mathrm{~h}$ to induce the elimination/fragmentation reaction. The reaction mixture from the $\mathrm{N}-\mathrm{S}$ cleavage step was cooled to room temperature and treated with iodomethane $(1.0 \mathrm{mmol}, 2.0$ equiv relative to the starting sulfonamide). The resulting mixture was aged at room temperature for $1 \mathrm{~h}$ to ensure full conversion. After complete conversion of the sulfinate, the reaction mixture was concentrated to dryness and the crude residue was purified by silica gel chromatography eluting with $0-10 \% \mathrm{MeOH}$ in DCM to afford $4 \mathbf{i}$ as a white solid in $72 \%$ yield. The yield was corrected for a small amount of DCM that remained with the product even after a prolonged time under vacuum.

${ }^{1} \mathrm{H}$ NMR (500 MHz, DMSO-d6) $\delta 8.76(\mathrm{~s}, 1 \mathrm{H}), 8.05(\mathrm{~s}, 1 \mathrm{H}), 7.97(\mathrm{~d}, J=8.4 \mathrm{~Hz}, 2 \mathrm{H}), 7.73(\mathrm{~d}, J=8.4 \mathrm{~Hz}$, 2H), $5.15-4.99(\mathrm{~m}, 2 \mathrm{H}), 3.26(\mathrm{~s}, 4 \mathrm{H}), 3.03-2.93(\mathrm{~m}, 1 \mathrm{H}), 2.23-1.85(\mathrm{~m}, 5 \mathrm{H}), 1.61$ (qd, J = 12.9, 5.7 $\mathrm{Hz}, 1 \mathrm{H}), 1.33$ (tdt, $J=10.3,7.3,3.8 \mathrm{~Hz}, 2 \mathrm{H}), 0.97-0.85(\mathrm{~m}, 1 \mathrm{H}), 0.56(\mathrm{tt}, J=7.2,3.5 \mathrm{~Hz}, 1 \mathrm{H})$.

${ }^{13} \mathrm{C}$ NMR $\left(126 \mathrm{MHz}\right.$, DMSO- $\left.d_{6}\right) \delta 173.36,151.20,138.67,137.65,131.60,128.45,127.43,125.54-$ $122.05(\mathrm{~m}), 120.34,119.84,51.49(\mathrm{~m}), 45.11(\mathrm{~m}), 43.52,36.16,34.94,32.42(\mathrm{~m}), 29.30(\mathrm{~m}), 19.40,15.47$ (m).

ESI MS: $531.25(\mathrm{M}+\mathrm{H})$ 


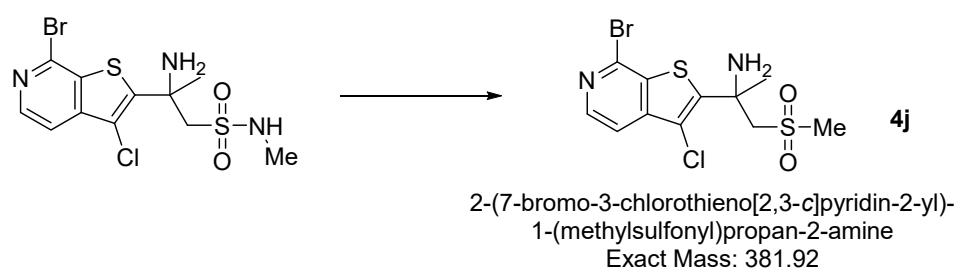

\section{2-(7-bromo-3-chlorothieno[2,3-c]pyridin-2-yl)-1-(methylsulfonyl)propan-2-amine (4j)}

To a screw-cap vial was added sulfonamide (1j, $0.50 \mathrm{mmol}, 1.0$ equiv), anhydrous THF (1.25 $\mathrm{mL})$, ethyl benzoylformate $(0.55 \mathrm{mmol}, 1.1$ equiv), and tris(dimethylamino)phosphine (0.6 mmol, 1.2 equiv). The reaction mixture is aged at ambient temperature for 30 minutes, during which time the secondary sulfonamide is converted to the $\mathrm{N}$-sulfonyl phenylglycine intermediate. Next, BTMG $(0.625 \mathrm{mmol}, 1.25$ equiv) is added, and the resulting mixture is heated at $65{ }^{\circ} \mathrm{C}$ for $4 \mathrm{~h}$ to induce the elimination/fragmentation reaction. The reaction mixture from the $\mathrm{N}-\mathrm{S}$ cleavage step was cooled to room temperature and treated with iodomethane $(1.0 \mathrm{mmol}, 2.0$ equiv relative to the starting sulfonamide). The resulting mixture was aged at room temperature for $1 \mathrm{~h}$ to ensure full conversion. After complete conversion of the sulfinate, the reaction mixture was concentrated to dryness and the crude residue was purified by silica gel chromatography eluting with $0-100 \%$ EtOAc in hexanes to afford $4 \mathbf{j}$ as a white solid in $79 \%$ yield.

${ }^{1} \mathrm{H}$ NMR $\left(500 \mathrm{MHz}\right.$, DMSO- $\left.d_{6}\right) \delta 8.38(\mathrm{~d}, J=5.5 \mathrm{~Hz}, 1 \mathrm{H}), 7.75(\mathrm{~d}, J=5.5 \mathrm{~Hz}, 1 \mathrm{H}), 4.08(\mathrm{~d}, J=14.7 \mathrm{~Hz}$, $1 \mathrm{H}), 3.79(\mathrm{~d}, J=14.7 \mathrm{~Hz}, 1 \mathrm{H}), 3.16(\mathrm{~s}, 2 \mathrm{H}), 3.00(\mathrm{~s}, 3 \mathrm{H}), 1.71(\mathrm{~s}, 3 \mathrm{H})$.

${ }^{13} \mathrm{C}$ NMR $(126 \mathrm{MHz}$, DMSO-d6) $\delta 156.56,144.83,144.36,134.73,133.64,115.26,113.52,61.14,53.80$, 43.34, 28.15.

ESI MS: 382.98, 384.92 (Major $\mathrm{M}+\mathrm{H}$ peaks, $\mathrm{Br} / \mathrm{Cl}$ isotopes) 


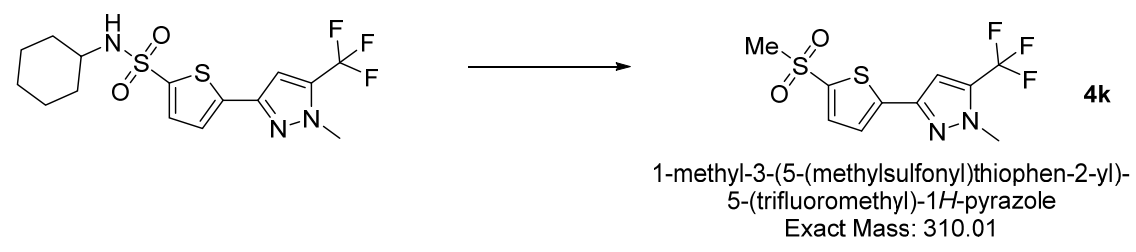

\section{1-methyl-3-(5-(methylsulfonyl)thiophen-2-yl)-5-(trifluoromethyl)-1H-pyrazole (4k)}

To a screw-cap vial was added sulfonamide ( $1 \mathbf{k}, 0.50 \mathrm{mmol}, 1.0$ equiv), anhydrous THF $(1.25 \mathrm{~mL})$, ethyl benzoylformate $(0.55 \mathrm{mmol}, 1.1$ equiv), and tris(dimethylamino)phosphine (0.6 mmol, 1.2 equiv). The reaction mixture is aged at ambient temperature for 30 minutes, during which time the secondary sulfonamide is converted to the $\mathrm{N}$-sulfonyl phenylglycine intermediate. Next, BTMG $(0.625 \mathrm{mmol}, 1.25$ equiv) is added, and the resulting mixture is heated at $65{ }^{\circ} \mathrm{C}$ for $4 \mathrm{~h}$ to induce the elimination/fragmentation reaction. The reaction mixture from the $\mathrm{N}$-S cleavage step was cooled to room temperature and treated with iodomethane $(1.0 \mathrm{mmol}, 2.0$ equiv relative to the starting sulfonamide). The resulting mixture was aged at room temperature for $1 \mathrm{~h}$ to ensure full conversion. After complete conversion of the sulfinate, the reaction mixture was concentrated to dryness and the crude residue was purified by silica gel chromatography eluting with $0-80 \%$ EtOAc in hexanes to afford $\mathbf{4 k}$ as a colorless oil in $55 \%$ yield.

${ }^{1} \mathrm{H}$ NMR $(500 \mathrm{MHz}$, DMSO-d6) $\delta 7.92(\mathrm{~d}, J=4.0 \mathrm{~Hz}, 1 \mathrm{H}), 7.67(\mathrm{~d}, J=4.0 \mathrm{~Hz}, 1 \mathrm{H}), 7.22(\mathrm{~s}, 1 \mathrm{H}), 4.06(\mathrm{~s}$, $3 \mathrm{H}), 3.43(\mathrm{~s}, 3 \mathrm{H})$.

${ }^{13} \mathrm{C}$ NMR $\left(126 \mathrm{MHz}\right.$, DMSO- $\left.d_{6}\right) \delta$ 143.09, 139.75 (q, $\left.J=37.8 \mathrm{~Hz}\right), 136.47,135.79,133.86,129.46,121.15$ (q, $J=268.3 \mathrm{~Hz}$ ), 105.97 (q, $J=2.1 \mathrm{~Hz}$ ), 45.20, 38.90.

ESI MS: $311.02(\mathrm{M}+\mathrm{H})$ 


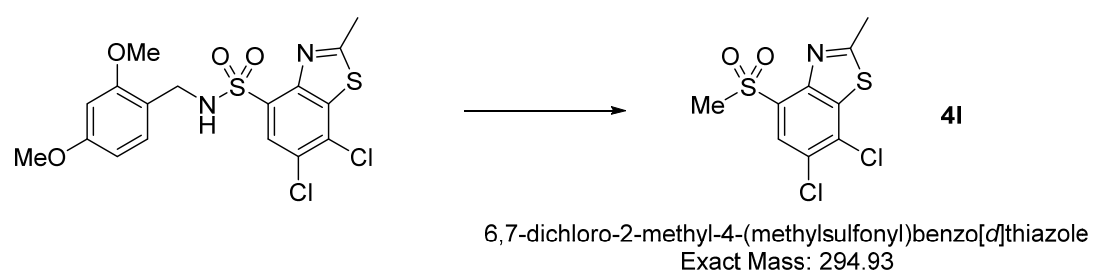

\section{6,7-dichloro-2-methyl-4-(methylsulfonyl)benzo[d]thiazole (4I)}

To a screw-cap vial was added sulfonamide (1I, $0.50 \mathrm{mmol}, 1.0$ equiv), anhydrous THF (1.25 mL), ethyl benzoylformate $(0.55 \mathrm{mmol}, 1.1$ equiv), and tris(dimethylamino)phosphine (0.6 mmol, 1.2 equiv). The reaction mixture is aged at ambient temperature for 30 minutes, during which time the secondary sulfonamide is converted to the $\mathrm{N}$-sulfonyl phenylglycine intermediate. Next, BTMG $(0.625 \mathrm{mmol}, 1.25$ equiv) is added, and the resulting mixture is heated at $65{ }^{\circ} \mathrm{C}$ for $4 \mathrm{~h}$ to induce the elimination/fragmentation reaction. The reaction mixture from the $\mathrm{N}-\mathrm{S}$ cleavage step was cooled to room temperature and treated with iodomethane $(1.0 \mathrm{mmol}, 2.0$ equiv relative to the starting sulfonamide). The resulting mixture was aged at room temperature for $1 \mathrm{~h}$ to ensure full conversion. After complete conversion of the sulfinate, the reaction mixture was concentrated to dryness and the crude residue was purified by silica gel chromatography eluting with $0-70 \%$ EtOAc in hexanes to afford $4 \mathrm{I}$ as a pale yellow solid in $71 \%$ yield.

${ }^{1} \mathrm{H}$ NMR (500 MHz, DMSO-d $)$ $\delta 8.07$ (s, 1H), 3.52 (s, 3H), 2.95 (s, 3H).

${ }^{13} \mathrm{C}$ NMR $(126 \mathrm{MHz}$, DMSO-d6) $\delta$ 172.89, 146.78, 139.24, 132.35, 129.06, 127.32, 126.69, 43.05, 20.39.

ESI MS: 295.94, 297.92 (Major $\mathrm{M}+\mathrm{H}$ peaks, Cl isotopes) 


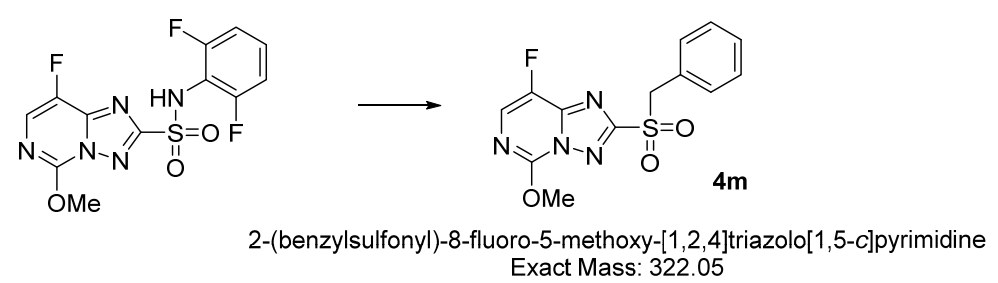

\section{2-(benzylsulfonyl)-8-fluoro-5-methoxy-[1,2,4]triazolo[1,5-c]pyrimidine (4m)}

To a screw-cap vial was added sulfonamide $(1 \mathrm{~m}, 0.50 \mathrm{mmol}, 1.0$ equiv), anhydrous THF $(1.25 \mathrm{~mL})$, ethyl benzoylformate $(0.55 \mathrm{mmol}, 1.1$ equiv), and tris(dimethylamino)phosphine (0.6 mmol, 1.2 equiv). The reaction mixture is aged at ambient temperature for 30 minutes, during which time the secondary sulfonamide is converted to the $\mathrm{N}$-sulfonyl phenylglycine intermediate. Next, BTMG $(0.625 \mathrm{mmol}, 1.25$ equiv) is added, and the resulting mixture aged at room temperature for $4 \mathrm{~h}$ to induce the elimination/fragmentation reaction. Note: the sulfinate intermediate is prone to loss of $\mathrm{SO}_{2}$, so the reaction mixture should be kept at room temperature during the elimination and subsequent functionalization steps. The reaction mixture from the N-S cleavage step was treated with benzyl bromide ( $1.0 \mathrm{mmol}, 2.0$ equiv relative to the starting sulfonamide). The resulting mixture was aged at room temperature for $1 \mathrm{~h}$ to ensure full conversion. After complete conversion of the sulfinate, the reaction mixture was concentrated to dryness and the crude residue was purified by silica gel chromatography eluting with $0-10 \% \mathrm{MeOH}$ in DCM to afford $4 \mathrm{~m}$ as a white solid in $38 \%$ yield. The yield was corrected for a small amount of EtOAc that remained with the product even after a prolonged time under vacuum. Note: the low yield is due to the loss of $\mathrm{SO}_{2}$ from the sulfinate intermediate.

${ }^{1} \mathrm{H}$ NMR $\left(500 \mathrm{MHz}, \mathrm{DMSO}-\mathrm{d}_{6}\right) \delta 8.38(\mathrm{~d}, J=2.1 \mathrm{~Hz}, 1 \mathrm{H}), 7.39-7.32(\mathrm{~m}, 5 \mathrm{H}), 5.00(\mathrm{~s}, 2 \mathrm{H}), 4.24(\mathrm{~s}, 3 \mathrm{H})$.

${ }^{13} \mathrm{C}$ NMR (126 MHz, DMSO- $\left.d_{6}\right) \delta 163.07,147.71(\mathrm{~d}, J=27.5 \mathrm{~Hz}), 146.44,144.28$ (d, $\left.J=251.5 \mathrm{~Hz}\right)$, $131.49,129.98$ (d, $J=21.8 \mathrm{~Hz}), 128.81,128.53,126.51,59.50,57.09$.

ESI MS: $323.10(M+H)$ 

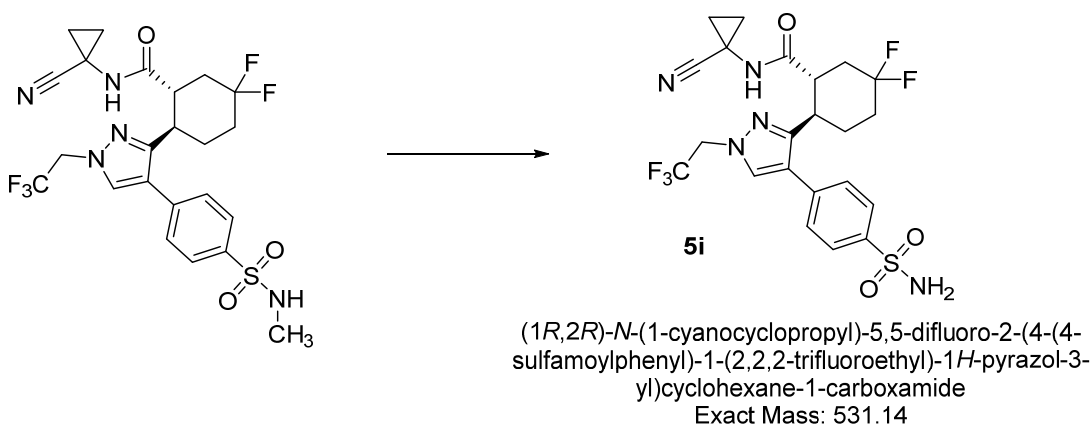

(1R,2R)-N-(1-cyanocyclopropyl)-5,5-difluoro-2-(4-(4-sulfamoylphenyl)-1-(2,2,2-trifluoroethyl)-1Hpyrazol-3-yl)cyclohexane-1-carboxamide (5i)

To a screw-cap vial was added sulfonamide (1i, $0.50 \mathrm{mmol}, 1.0$ equiv), anhydrous THF (1.25 mL), ethyl benzoylformate $(0.55 \mathrm{mmol}, 1.1$ equiv), and tris(dimethylamino)phosphine (0.6 mmol, 1.2 equiv). The reaction mixture is aged at ambient temperature for 30 minutes, during which time the secondary sulfonamide is converted to the $\mathrm{N}$-sulfonyl phenylglycine intermediate. Next, BTMG $(0.625 \mathrm{mmol}, 1.25$ equiv) is added, and the resulting mixture is heated at $65{ }^{\circ} \mathrm{C}$ for $4 \mathrm{~h}$ to induce the elimination/fragmentation reaction. The reaction mixture from the $\mathrm{N}-\mathrm{S}$ cleavage step was cooled to room temperature and treated with $\mathrm{NH}_{3}(7 \mathrm{M}$ in $\mathrm{MeOH}, 3.0$ equiv relative to the starting sulfonamide) and iodine ( $0.55 \mathrm{mmol}, 1.10$ equiv). The resulting mixture was aged at room temperature for $2 \mathrm{~h}$ to ensure full conversion. After complete conversion of the sulfinate, the reaction mixture was concentrated to dryness and the crude residue was purified by silica gel chromatography eluting with $0-100 \%$ EtOAc in hexanes to afford $\mathbf{5 i}$ as a white solid in $77 \%$ yield. The yield was corrected for a small amount of EtOAc that remained with the product even after a prolonged time under vacuum.

${ }^{1} \mathrm{H}$ NMR $\left(500 \mathrm{MHz}, \mathrm{DMSO}-\mathrm{d}_{6}\right) \delta 8.74(\mathrm{~s}, 1 \mathrm{H}), 8.00(\mathrm{~s}, 1 \mathrm{H}), 7.86(\mathrm{~d}, J=8.4 \mathrm{~Hz}, 2 \mathrm{H}), 7.64(\mathrm{~d}, J=8.4 \mathrm{~Hz}$, $2 \mathrm{H}), 7.38(\mathrm{~s}, 2 \mathrm{H}), 5.14-4.98(\mathrm{~m}, 2 \mathrm{H}), 3.23(\mathrm{td}, J=11.7,3.1 \mathrm{~Hz}, 1 \mathrm{H}), 3.02-2.93(\mathrm{~m}, 1 \mathrm{H}), 2.22-1.99(\mathrm{~m}$, $3 \mathrm{H}), 1.97-1.84(\mathrm{~m}, 1 \mathrm{H}), 1.60(\mathrm{qd}, J=12.9,5.6 \mathrm{~Hz}, 1 \mathrm{H}), 1.40-1.28(\mathrm{~m}, 2 \mathrm{H}), 0.95-0.87(\mathrm{~m}, 1 \mathrm{H}), 0.61-$ $0.54(\mathrm{~m}, 1 \mathrm{H})$.

${ }^{13} \mathrm{C}$ NMR $\left(126 \mathrm{MHz}\right.$, DMSO- $\left.d_{6}\right) \delta 173.37,151.13,142.07,135.85,131.33,128.13,126.12,125.53-$ 121.40 (m; overlapping peaks), 120.38, 120.11, 51.48 (q, $J=33.5 \mathrm{~Hz}), 45.07$ (d, $J=9.5 \mathrm{~Hz}), 36.15(\mathrm{t}, J=$ 24.7 Hz), 32.52 (t, $J=23.5 \mathrm{~Hz}$ ), 29.25 (d, $J=10.0 \mathrm{~Hz}$ ), 20.07 (d, $J=167.5 \mathrm{~Hz}$ ), 15.49 (d, $J=52.5 \mathrm{~Hz}$ ). 

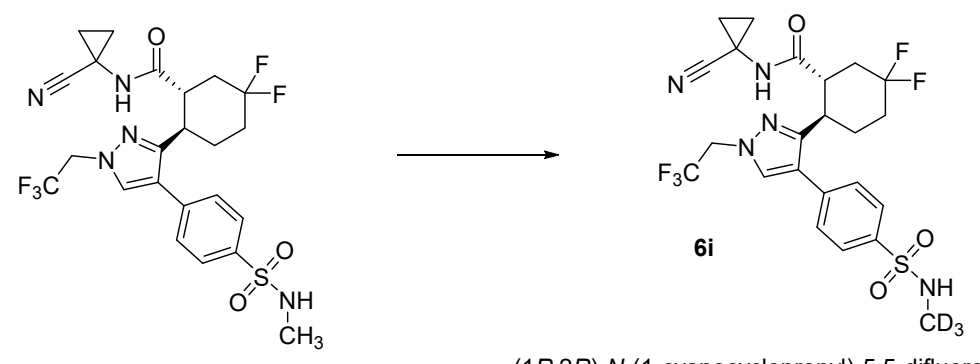

(1R,2R)-N-(1-cyanocyclopropyl)-5,5-difluoro-2-(4-(4- $(N$ (methyl- $\left.d_{3}\right)$ sulfamoyl)phenyl)-1-(2,2,2-trifluoroethyl)-1 $\mathrm{H}$ pyrazol-3-yl)cyclohexane-1-carboxamide

$$
\text { Exact Mass: } 548.17
$$

\section{(1R,2R)-N-(1-cyanocyclopropyl)-5,5-difluoro-2-(4-(4-(N-(methyl-d3)sulfamoyl)phenyl)-1-(2,2,2- trifluoroethyl)-1H-pyrazol-3-yl)cyclohexane-1-carboxamide (6i)}

To a round bottom flask was added sulfonamide $(\mathbf{1 i}, 3.00 \mathrm{~g}, 5.50 \mathrm{mmol}, 1.00$ equiv), anhydrous THF $(13.8 \mathrm{~mL})$, and ethyl benzoylformate $(6.05 \mathrm{mmol}, 1.10$ equiv). Tris(dimethylamino)phosphine (6.60 mmol, 1.20 equiv) was added dropwise over 3 minutes The reaction mixture was aged at ambient temperature for 30 minutes, during which time the secondary sulfonamide is converted to the $\mathrm{N}$-sulfonyl phenylglycine intermediate. Note: for high isotopic purity of the final product, it is essential that there is no remaining $1 \mathbf{i}$ left in the reaction mixture. Next, BTMG (13.8 mmol, 2.50 equiv) is added, and the resulting mixture is heated at $65{ }^{\circ} \mathrm{C}$ for $4 \mathrm{~h}$ to induce the elimination/fragmentation reaction. Note: the higher charge of BMTG in this reaction is to neutralize the methylammonium salt in the next step. The reaction mixture from the $\mathrm{N}-\mathrm{S}$ cleavage step was cooled to room temperature and treated with $\mathrm{CD}_{3} \mathrm{NH}_{3} \mathrm{Cl}(11.0 \mathrm{mmol}, 2.0$ equiv relative to the starting sulfonamide) and iodine $(6.05 \mathrm{mmol}, 1.10$ equiv). The resulting mixture was aged at room temperature for $2 \mathrm{~h}$ to ensure full conversion. After complete conversion of the sulfinate, the reaction mixture was concentrated to dryness and the crude residue was purified by silica gel chromatography eluting with $0-100 \%$ EtOAc in hexanes to afford $\mathbf{5 i}$ as a white solid in $73 \%$ yield. The yield was corrected for a small amount of EtOAc that remained with the product even after a prolonged time under vacuum. The isotopic purity was determined by mass spectrometry to be $>99 \%$.

1H NMR (500 MHz, DMSO-d6) $\delta 8.76(\mathrm{~s}, 1 \mathrm{H}), 8.03(\mathrm{~s}, 1 \mathrm{H}), 7.83-7.78(\mathrm{~m}, 2 \mathrm{H}), 7.73-7.66(\mathrm{~m}, 2 \mathrm{H}), 7.45$ $(\mathrm{s}, 1 \mathrm{H}), 5.15-4.98(\mathrm{~m}, 2 \mathrm{H}), 3.25(\mathrm{td}, \mathrm{J}=12.0,3.4 \mathrm{~Hz}, 1 \mathrm{H}), 3.03-2.93(\mathrm{~m}, 1 \mathrm{H}), 2.22-1.99(\mathrm{~m}, 4 \mathrm{H}), 1.97$ $-1.84(\mathrm{~m}, 1 \mathrm{H}), 1.67-1.52(\mathrm{~m}, 1 \mathrm{H}), 1.39-1.28(\mathrm{~m}, 2 \mathrm{H}), 0.95-0.87(\mathrm{~m}, 1 \mathrm{H}), 0.61-0.53(\mathrm{~m}, 1 \mathrm{H})$.

${ }^{13} \mathrm{C}$ NMR $\left(126 \mathrm{MHz}, \mathrm{DMSO}-d_{6}\right) \delta 173.38,151.19,137.27,136.44,131.45,128.30,127.13,126.88-$ $123.48(\mathrm{~m}), 121.97$ (d, $J=94.9 \mathrm{~Hz}), 120.37,119.94,51.49$ (q, $J=33.6 \mathrm{~Hz}), 45.08$ (d, J = 9.6 Hz), 36.18 $(\mathrm{t}, J=24.5 \mathrm{~Hz}), 34.94,32.51(\mathrm{t}, J=23.5 \mathrm{~Hz}), 29.31(\mathrm{~d}, J=10.1 \mathrm{~Hz}), 19.40,15.70,15.27$.

ESI MS: $549.33(\mathrm{M}+\mathrm{H})$ 
<smiles>CCCC(=O)Nc1ccc(F)c(C(=O)c2c[nH]c3ncc(-c4ccc(Cl)cc4)cc23)c1F</smiles>

1H NMR (500 MHz, DMSO-d6)

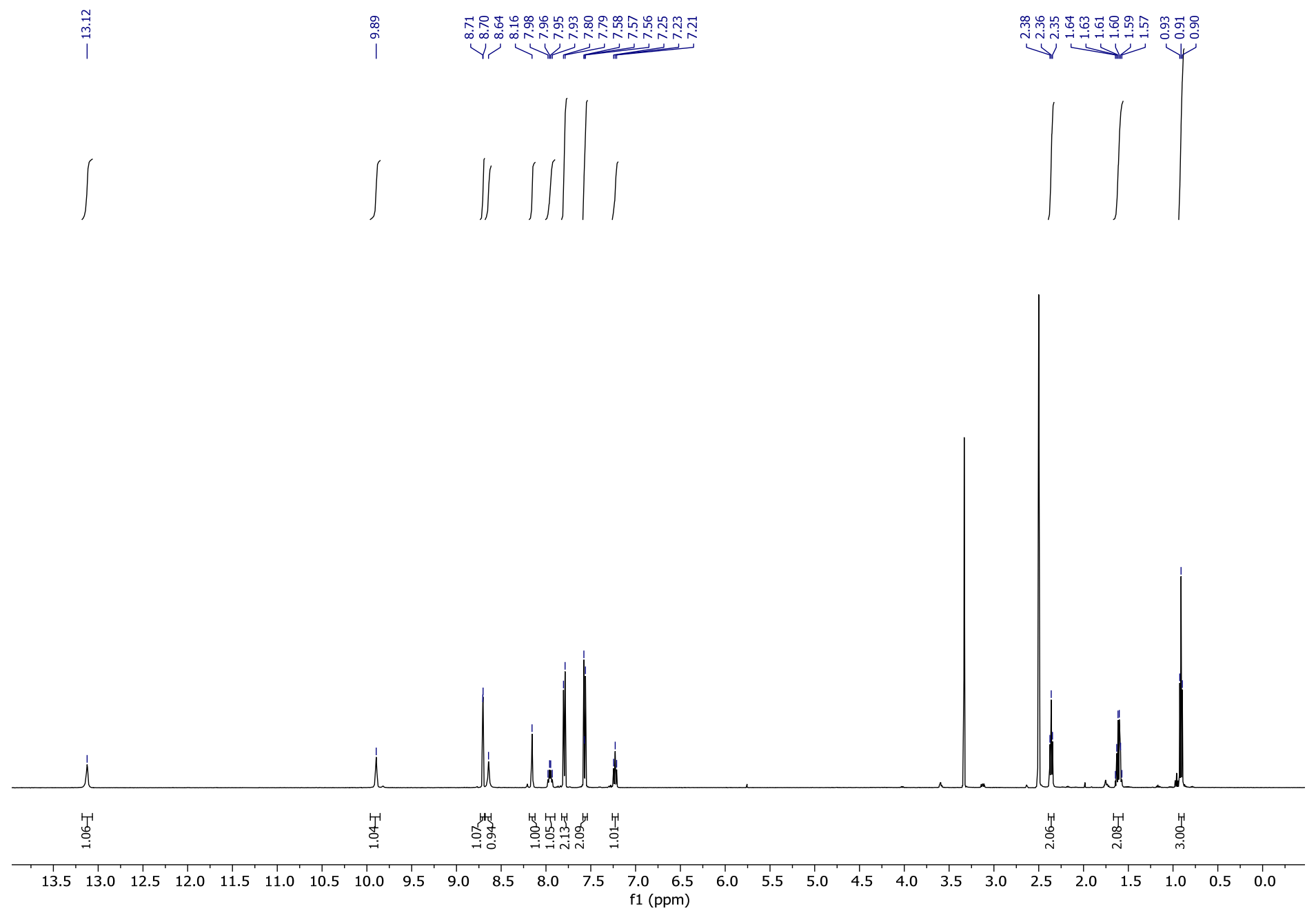


<smiles>CCCC(=O)Nc1ccc(F)c(C(=O)c2c[nH]c3ncc(-c4ccc(Cl)cc4)cc23)c1F</smiles>

13C NMR (126 MHz, DMSO-d6)
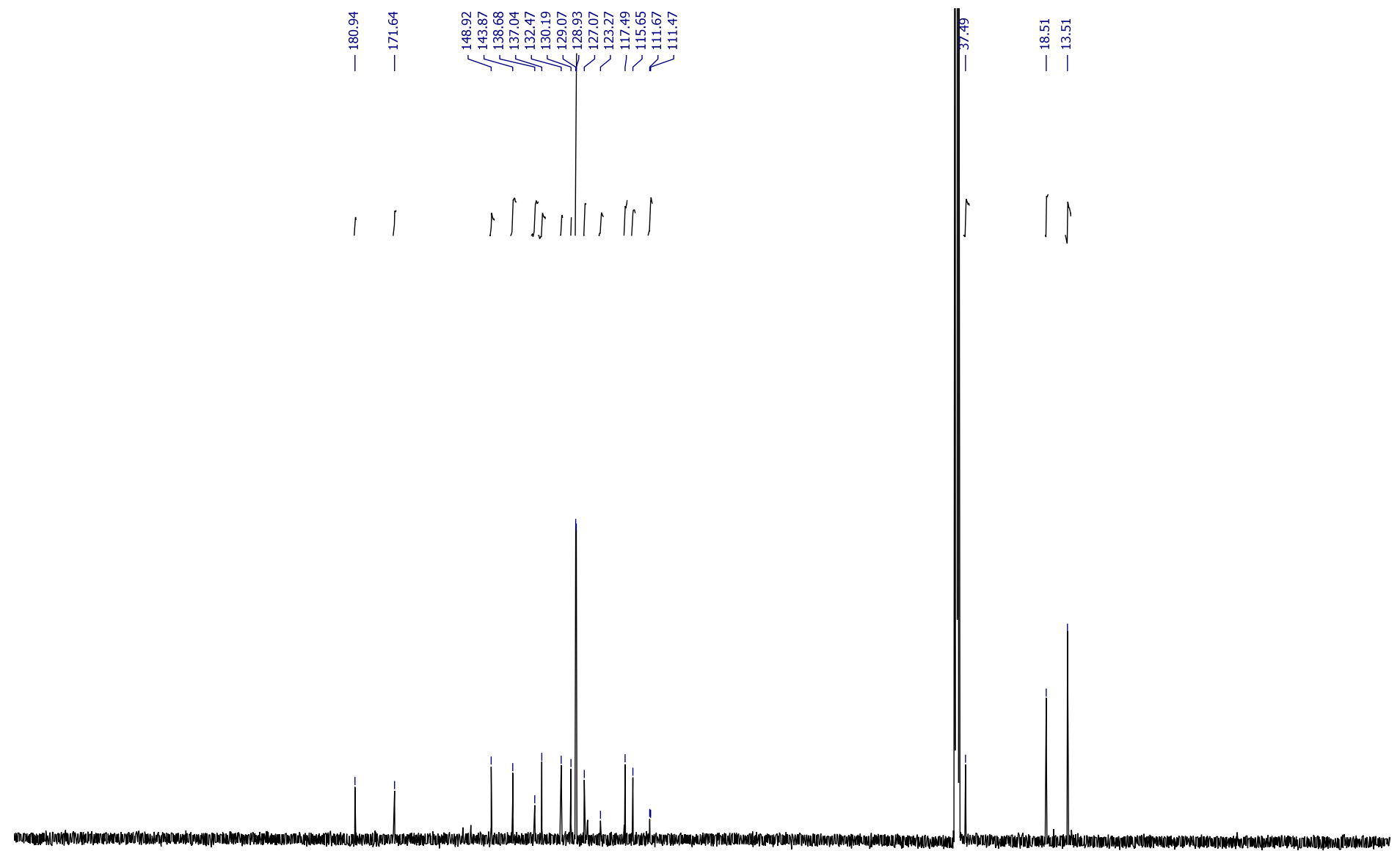

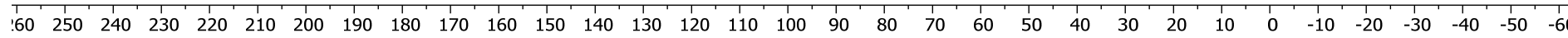
f1 (ppm) 
<smiles>COc1ncc(-c2cc(OS(=O)(=O)C(F)(F)F)cc3c2CNC3=O)cc1NC(C)=O</smiles>

1H NMR (500 MHz, DMSO-d6)
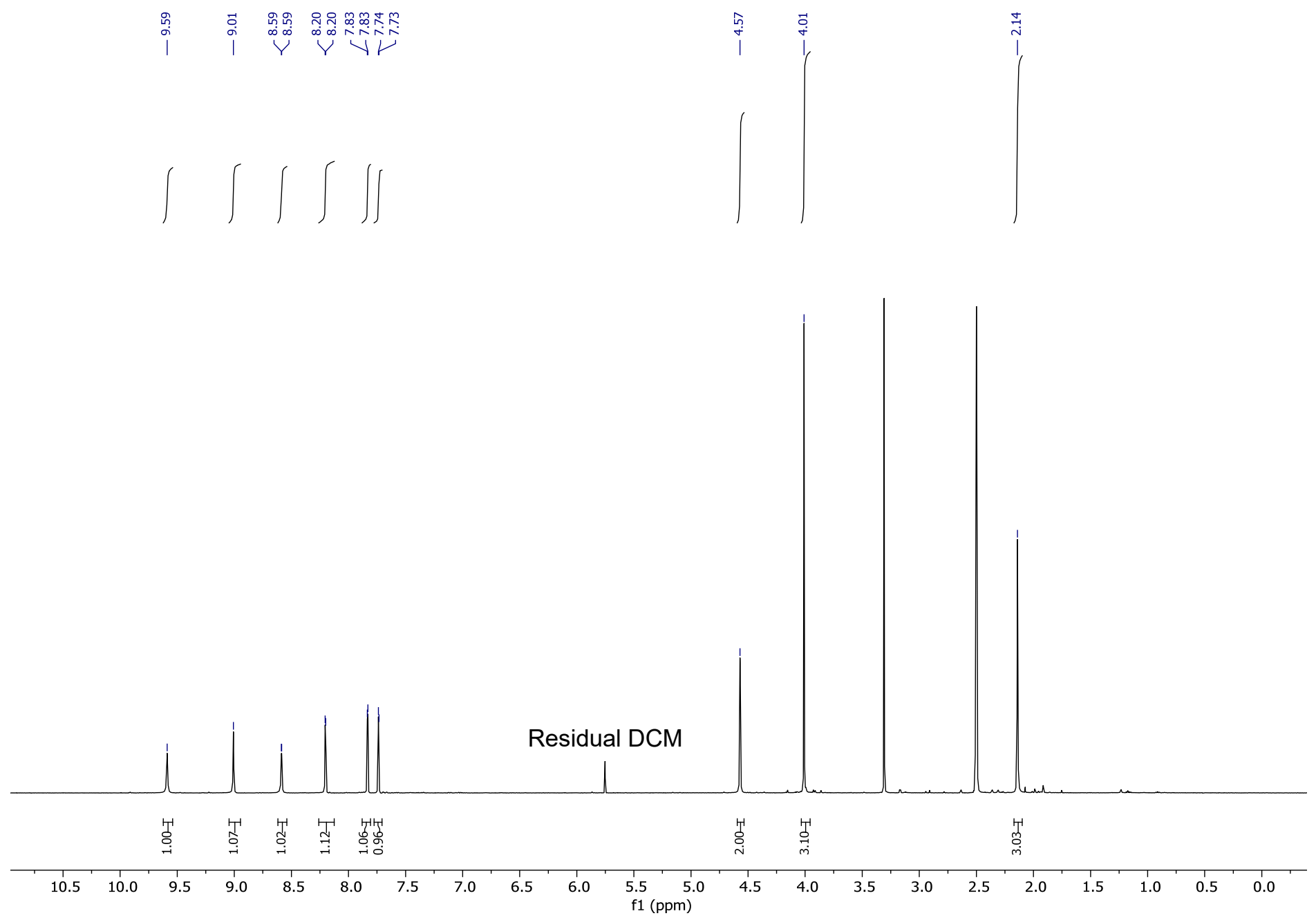
<smiles>[CH]C(=O)Nc1cc(-c2cc(OS(=O)(=O)C(F)(F)F)cc3c2CNC3=O)cnc1OC</smiles>

13C NMR (126 MHz, DMSO-d6)
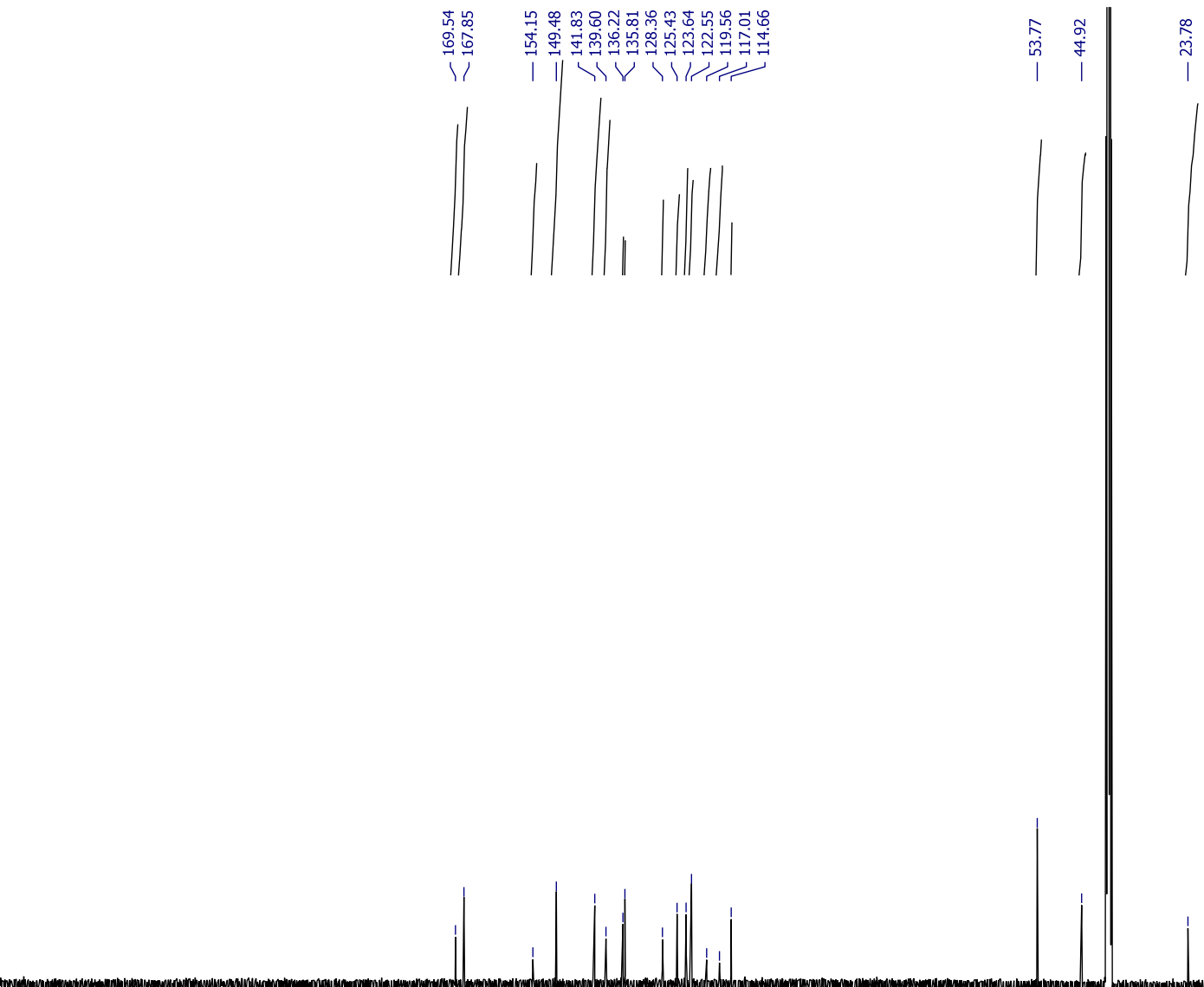

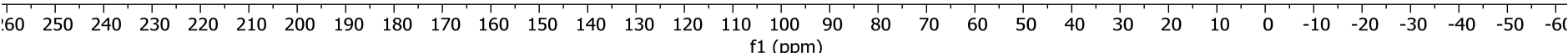


<smiles>CC(C)(C)c1nc(-c2cccc(NC(=O)c3ccccc3)c2F)c(-c2ccnc(N)n2)s1</smiles>

1H NMR (500 MHz, DMSO-d6)
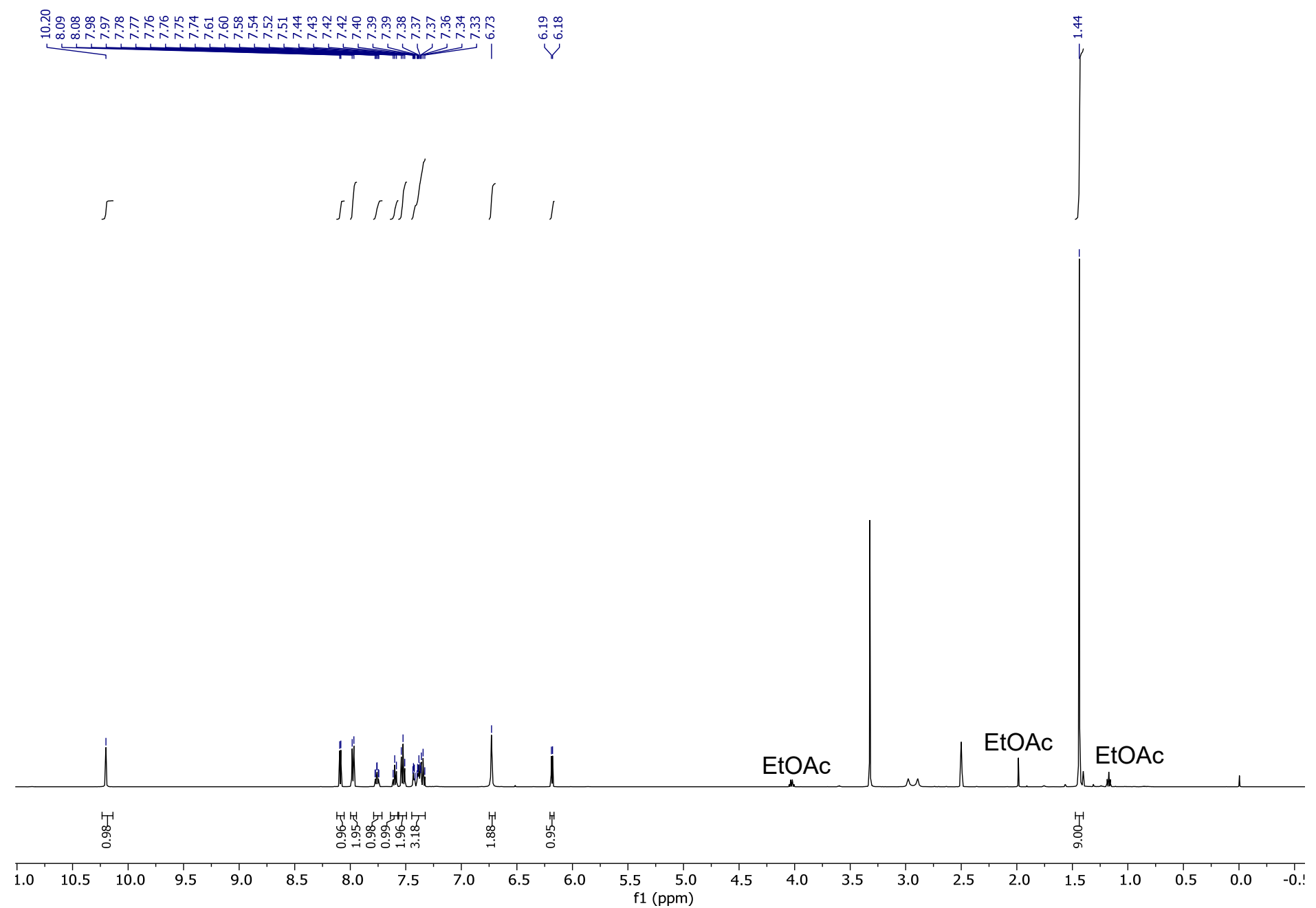
<smiles>CC(C)(C)c1nc(-c2cccc(NC(=O)c3ccccc3)c2F)c(-c2ccnc(N)n2)s1</smiles>

13C NMR (126 MHz, DMSO-d6)
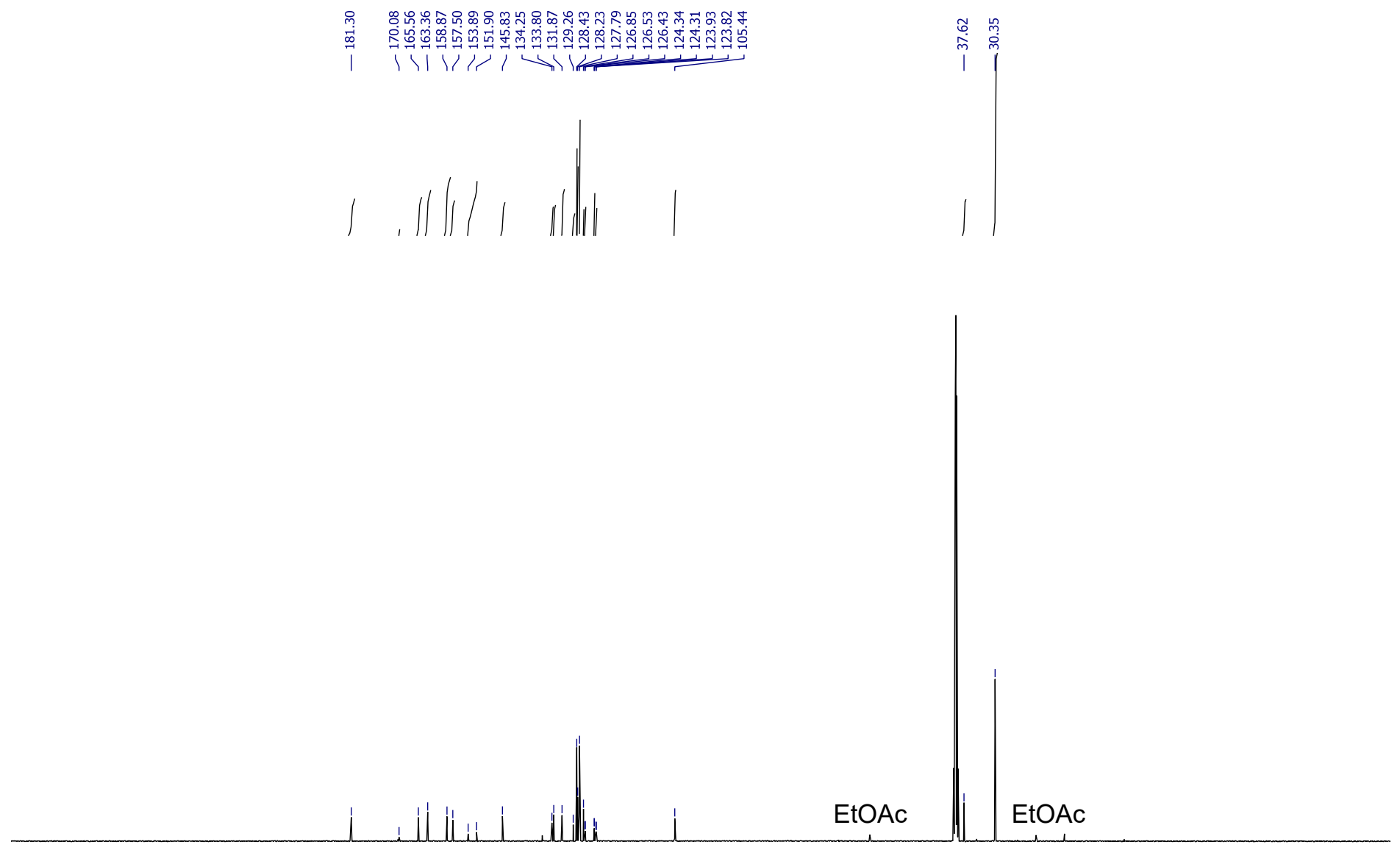

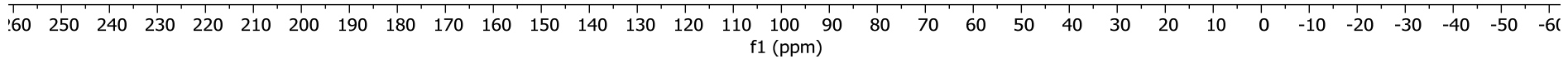


<smiles>CS(=O)(=O)c1ccc(-c2cn(CC(F)(F)F)nc2[C@@H]2CCC(F)(F)C[C@H]2C(=O)NC2(C#N)CC2)cc1</smiles>

1H NMR (500 MHz, DMSO-d6)

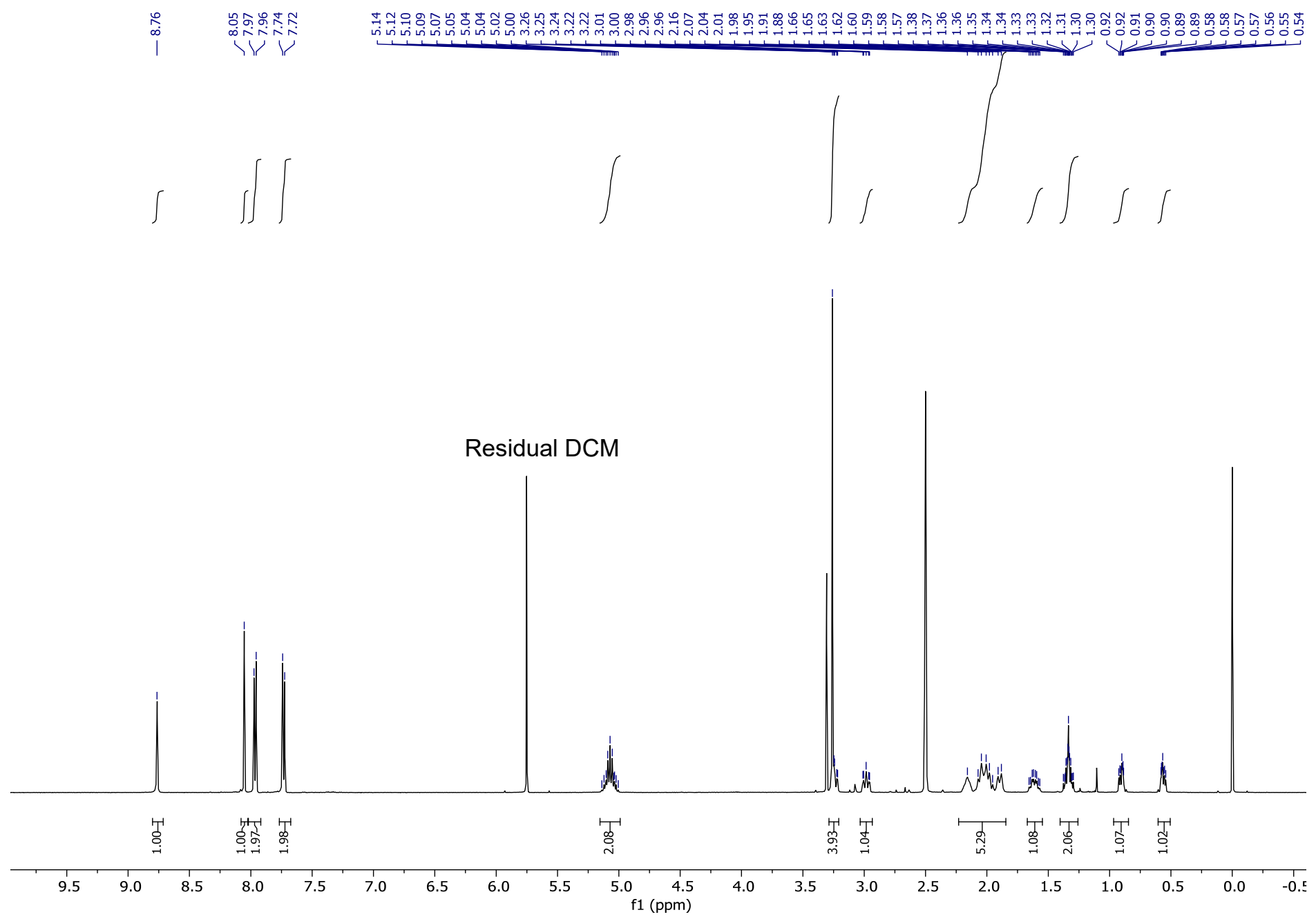


<smiles>CS(=O)(=O)c1ccc(-c2cn(CC(F)(F)F)nc2[C@@H]2CCC(F)(F)C[C@H]2C(=O)NC2(C#N)CC2)cc1</smiles>

13C NMR (126 MHz, DMSO-d6)

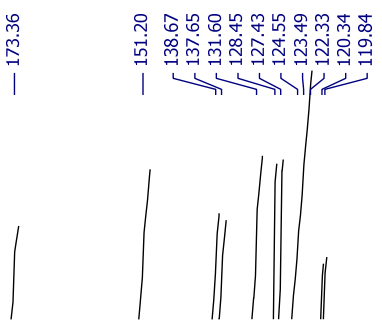

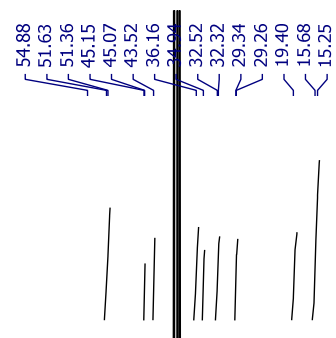

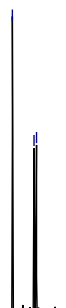

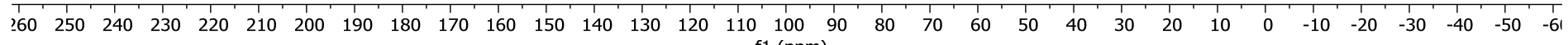
f1 (ppm) 
<smiles>CS(=O)(=O)CC(N)(CS(C)(=O)=O)c1sc2c(Br)nccc2c1Cl</smiles>

1H NMR (500 MHz, DMSO-d6)
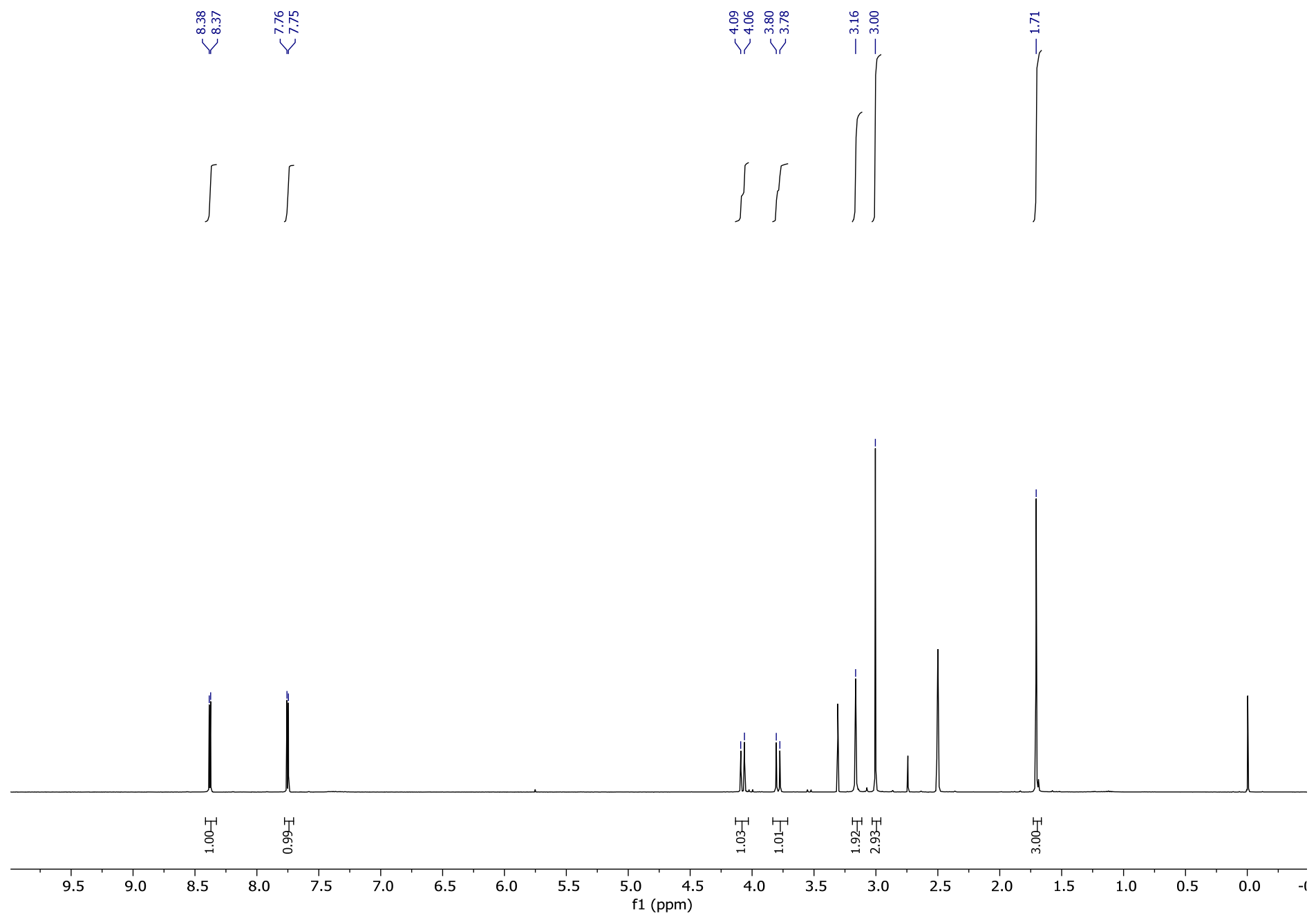
<smiles>CC(N)(CS(C)(=O)=O)c1sc2c(Br)nccc2c1Cl</smiles>

13C NMR (126 MHz, DMSO-d6)

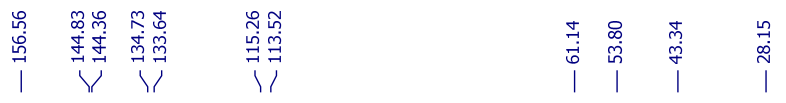

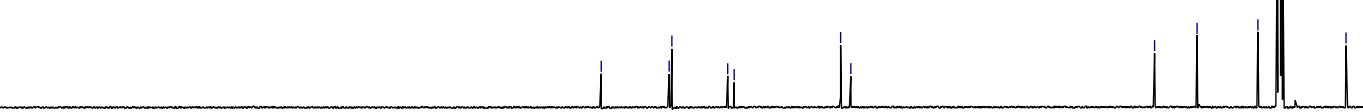

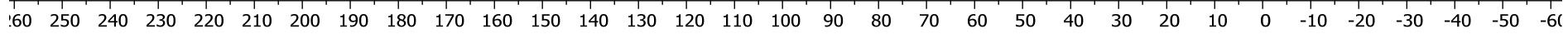




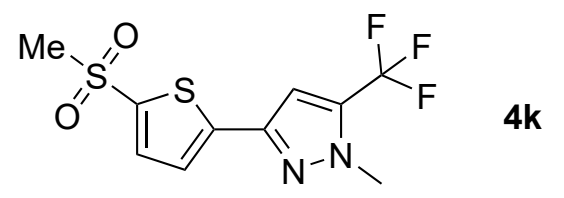

1H NMR (500 MHz, DMSO-d6)

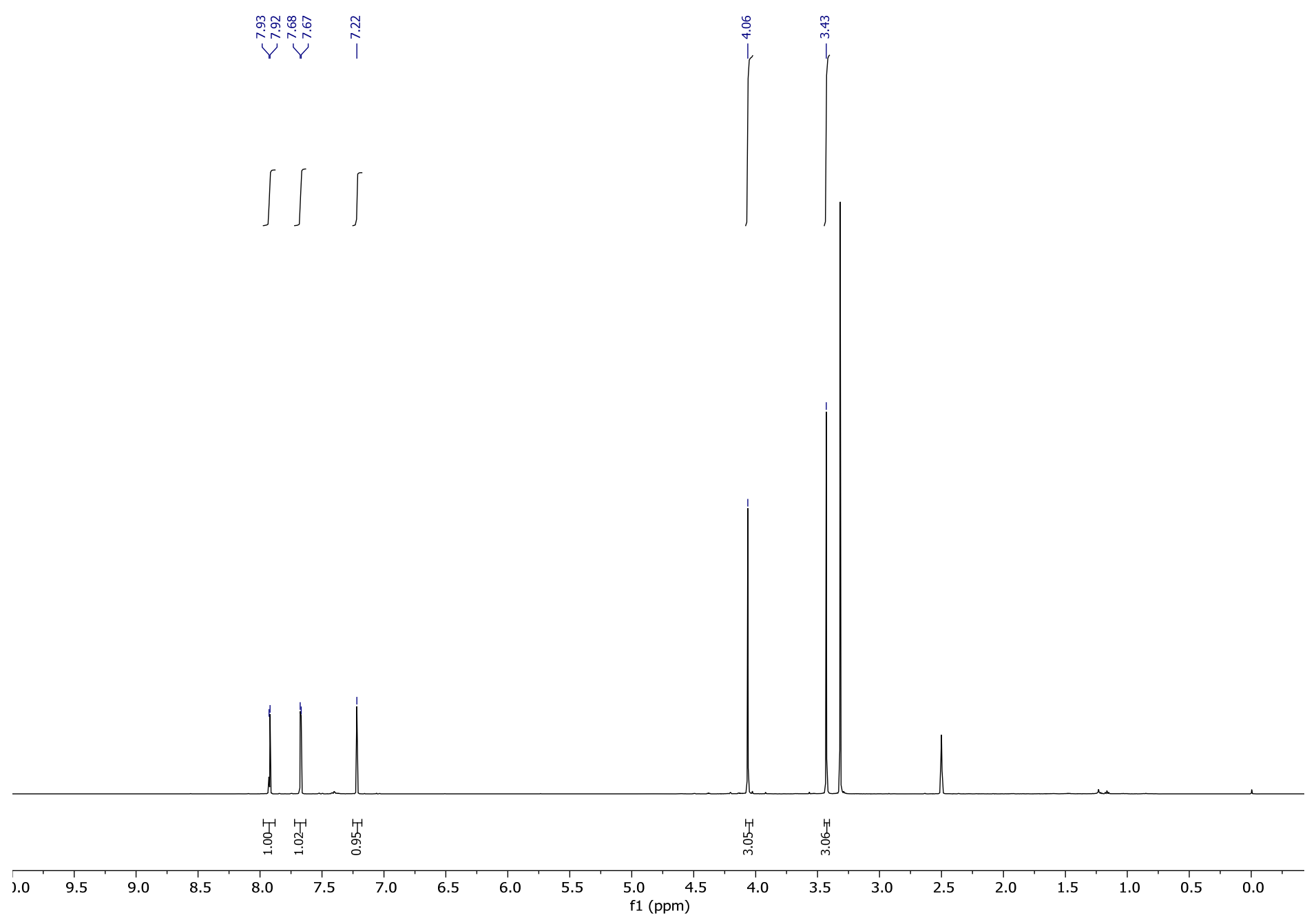


<smiles>Cn1nc(-c2ccc(S(C)(=O)=O)s2)cc1C(F)(F)F</smiles>

13C NMR (126 MHz, DMSO-d6)
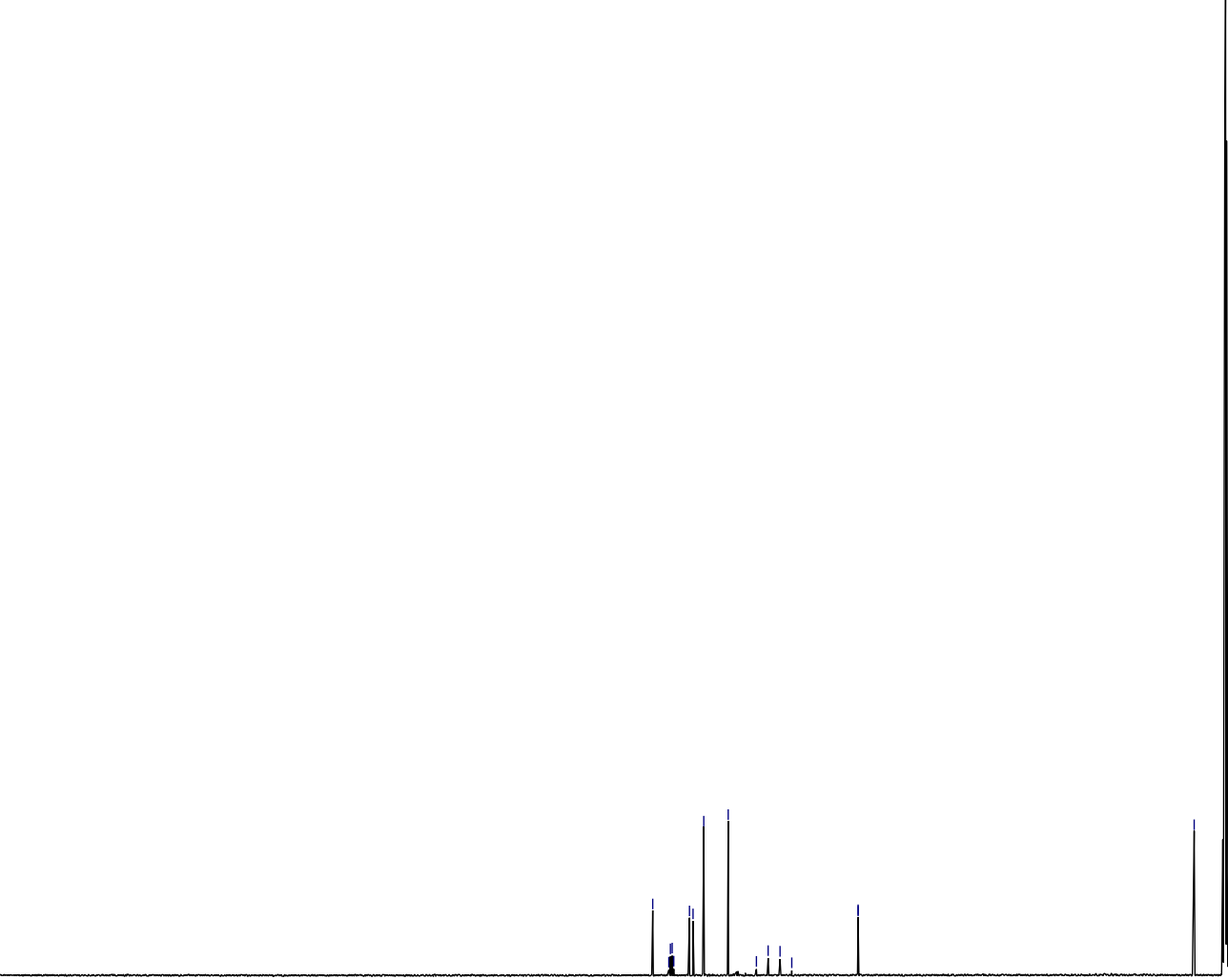

\begin{tabular}{lllllllllllllllllllllllllllllllllllll}
\hline 60 & 250 & 240 & 230 & 220 & 210 & 200 & 190 & 180 & 170 & 160 & 150 & 140 & 130 & 120 & 110 & 100 & 90 & 80 & 70 & 60 & 50 & 40 & 30 & 20 & 10 & 0 & -10 & -20 & -30 & -40 & -50 & -61
\end{tabular} 


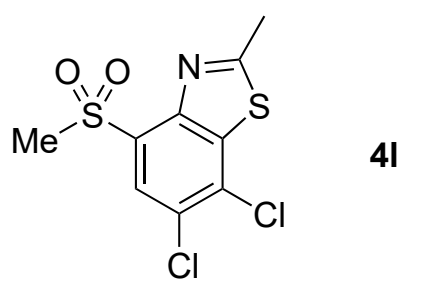

1H NMR (500 MHz, DMSO-d6)
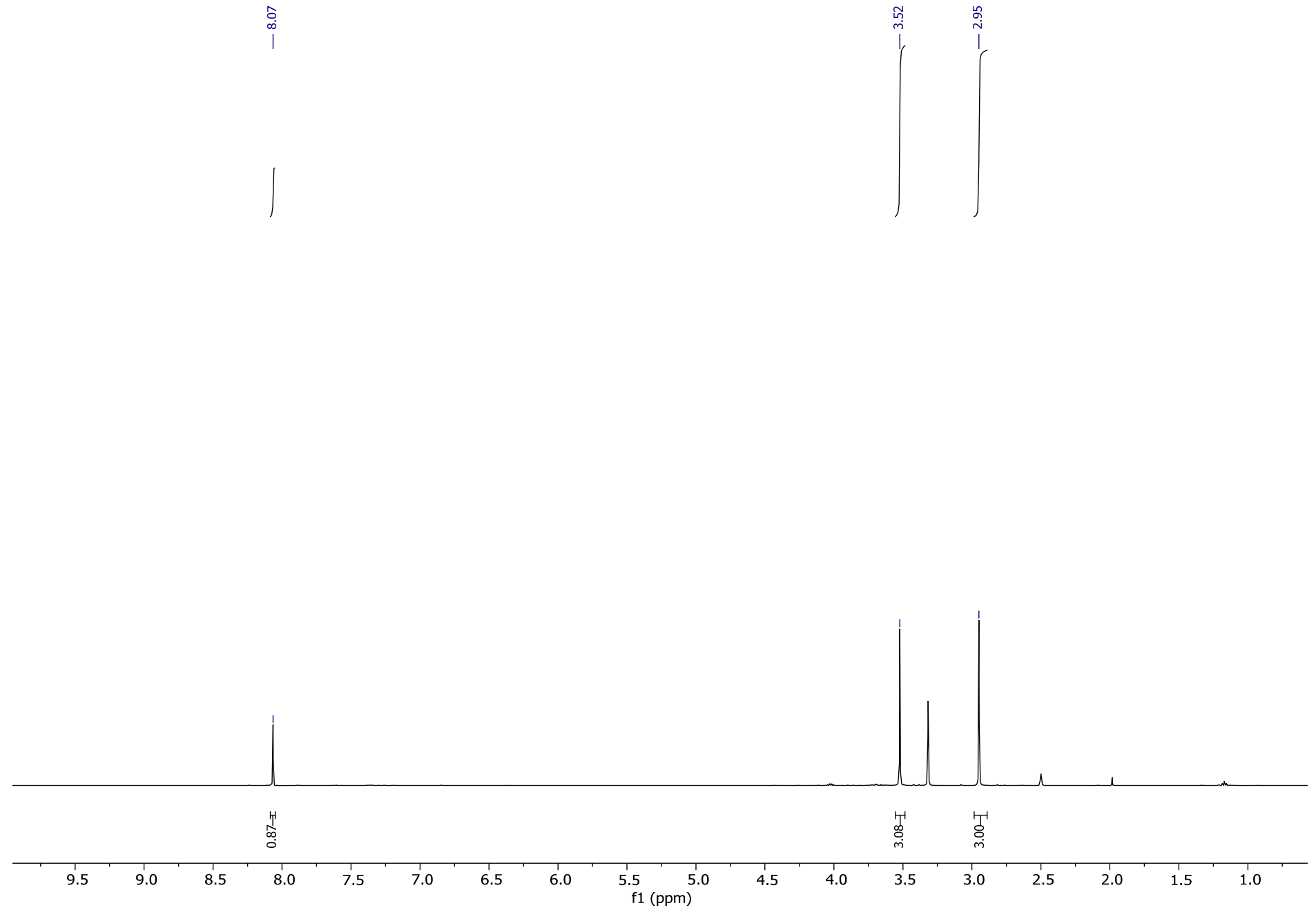


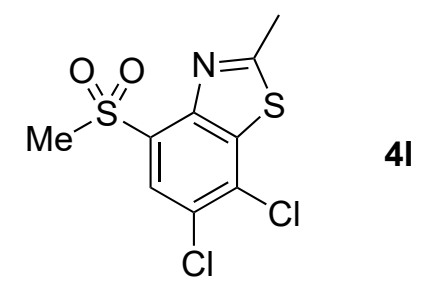

13C NMR (126 MHz, DMSO-d6)

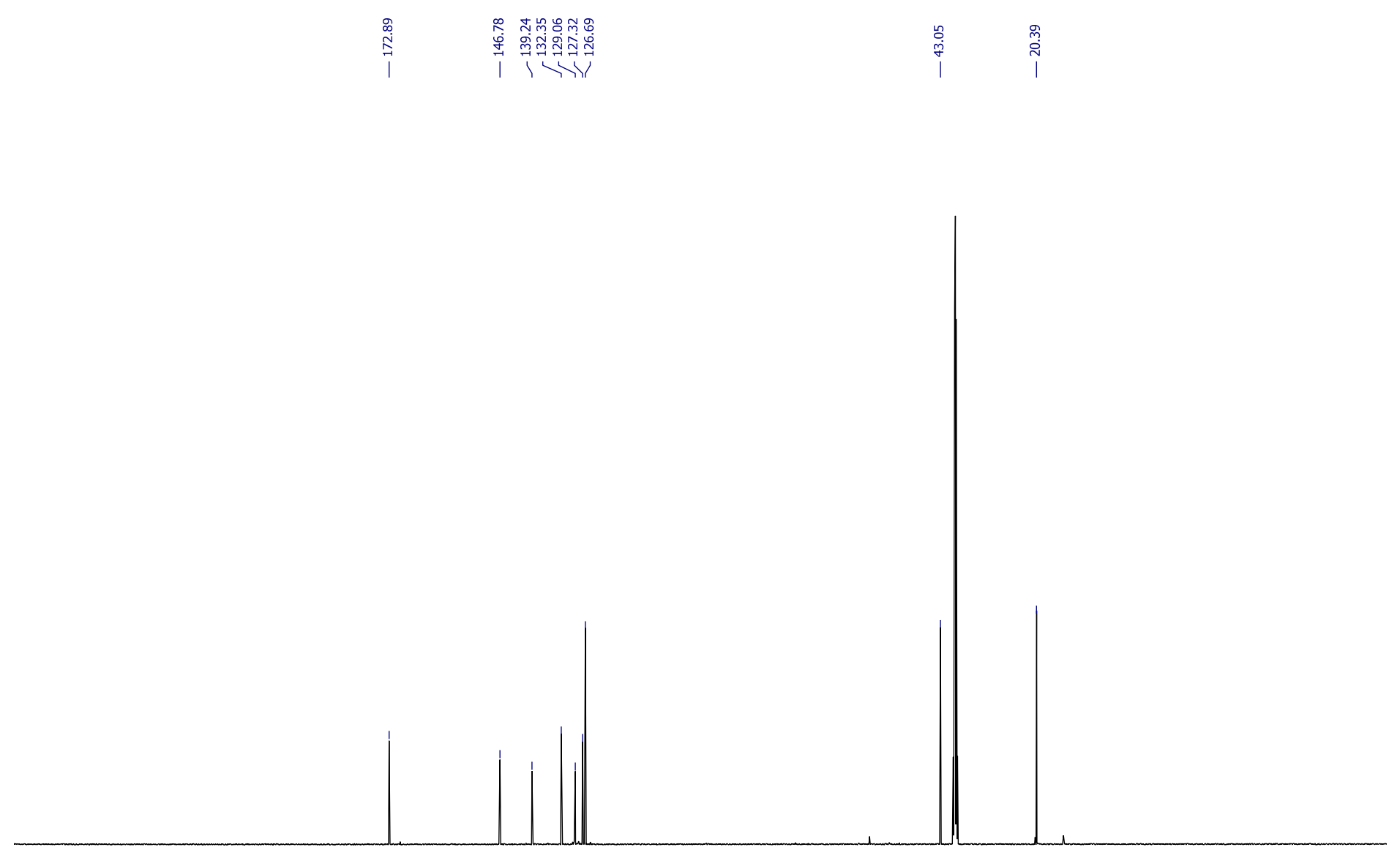

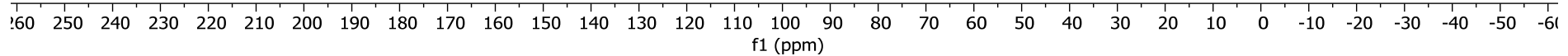




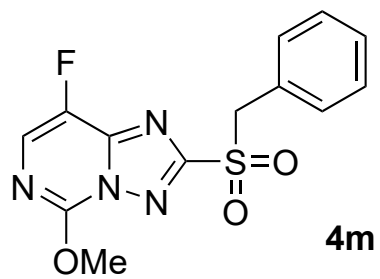

1H NMR (500 MHz, DMSO-d6)
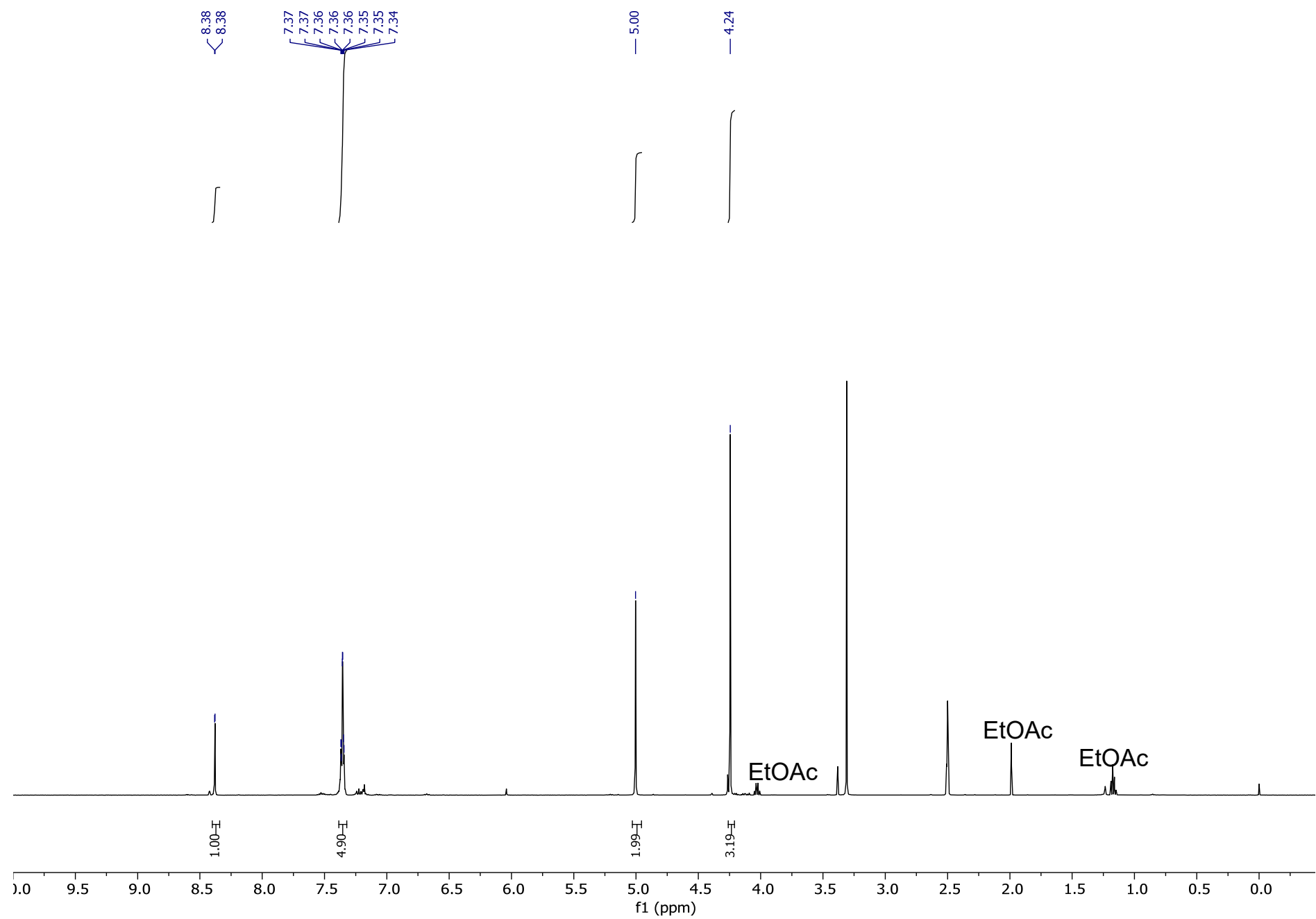


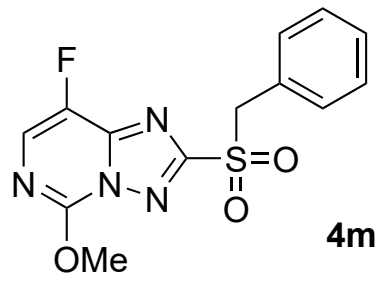

13C NMR (126 MHz, DMSO-d6)

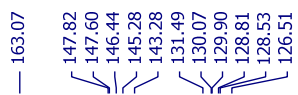

웅ำ

11

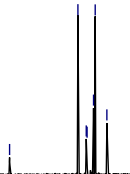

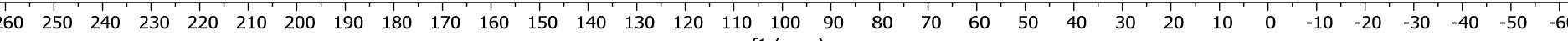
f1 (ppm) 
1H NMR (500 MHz, DMSO-d6)<smiles>N#CC1(NC(=O)[C@@H]2CC(F)(F)CC[C@H]2c2nn(CC(F)(F)F)cc2-c2ccc(S(N)(=O)=O)cc2)CC1</smiles>
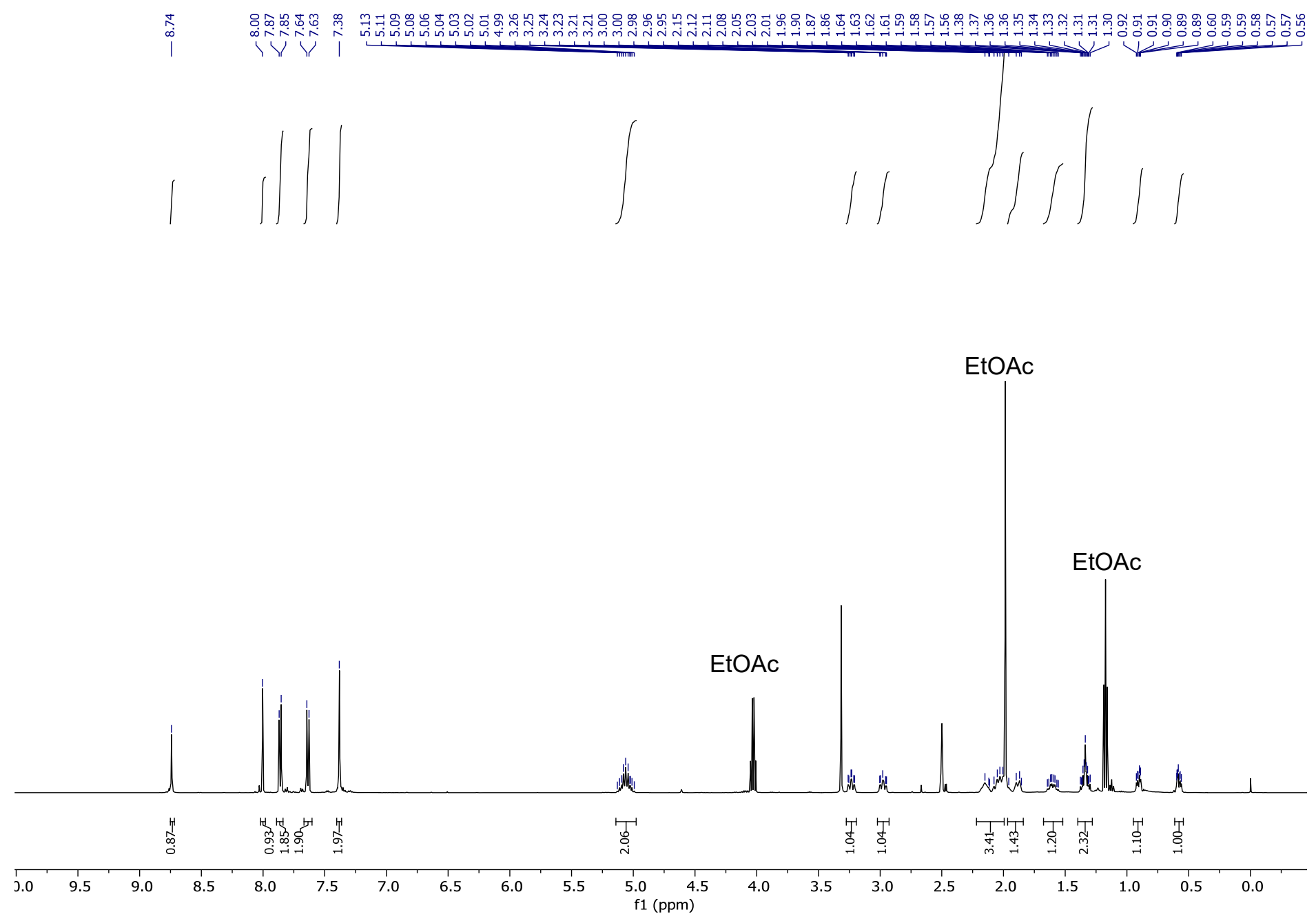
13C NMR (126 MHz, DMSO-d6)<smiles>N#CC1(NC(=O)[C@@H]2CC(F)(F)CC[C@H]2c2nn(CC(F)(F)F)cc2-c2ccc(S(N)(=O)=O)cc2)CC1</smiles>

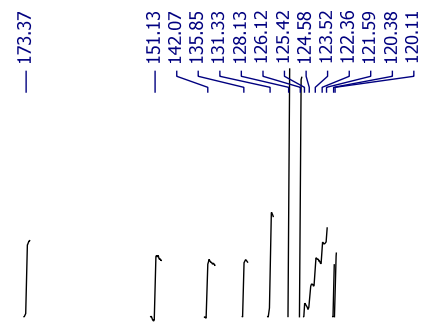

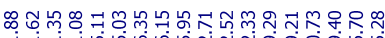

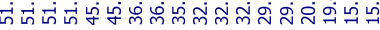
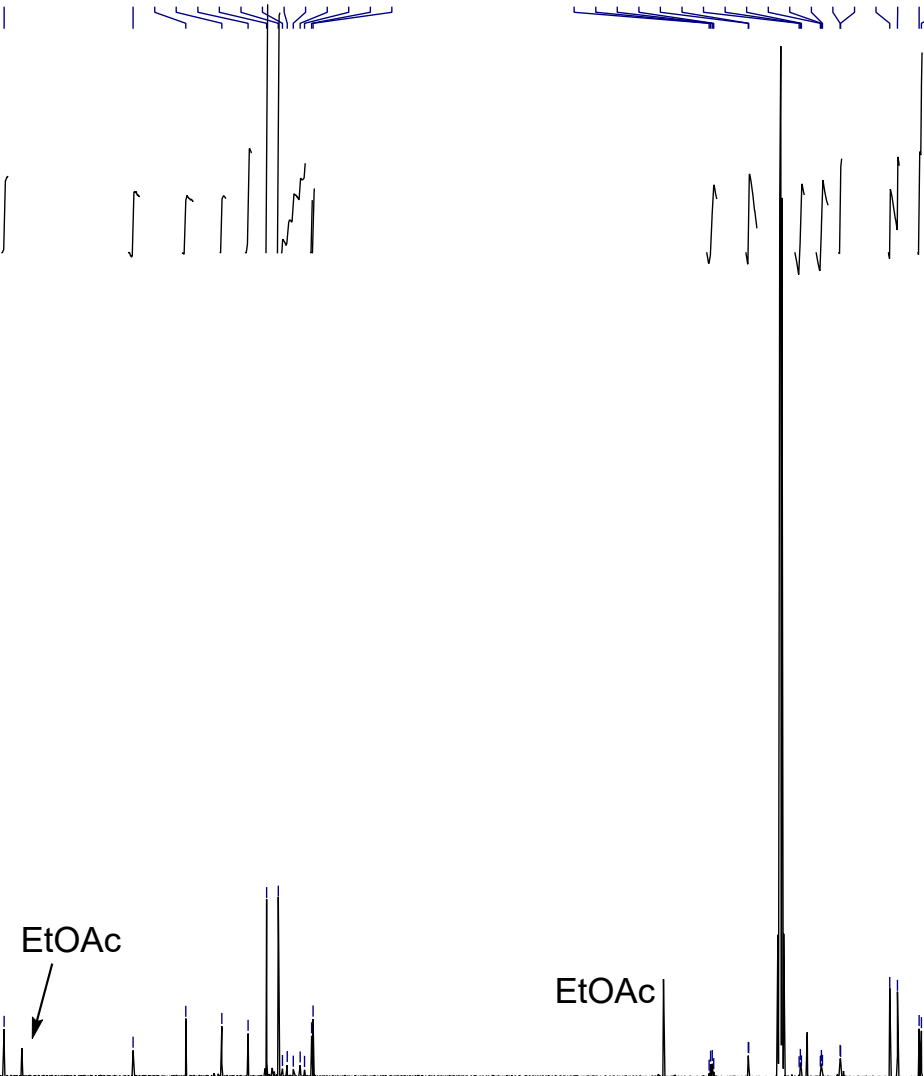

EtOAc

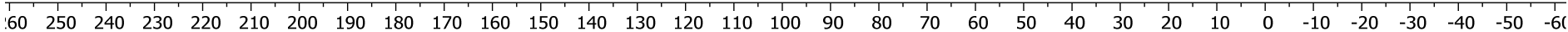
$\mathrm{f1}(\mathrm{ppm})$ 
1H NMR (500 MHz, DMSO-d6)<smiles>CC(C)(C)NS(=O)(=O)c1ccc(-c2cn(CC(F)(F)F)nc2[C@@H]2CCC(F)(F)C[C@H]2C(=O)NC2(C#N)CC2)cc1</smiles>
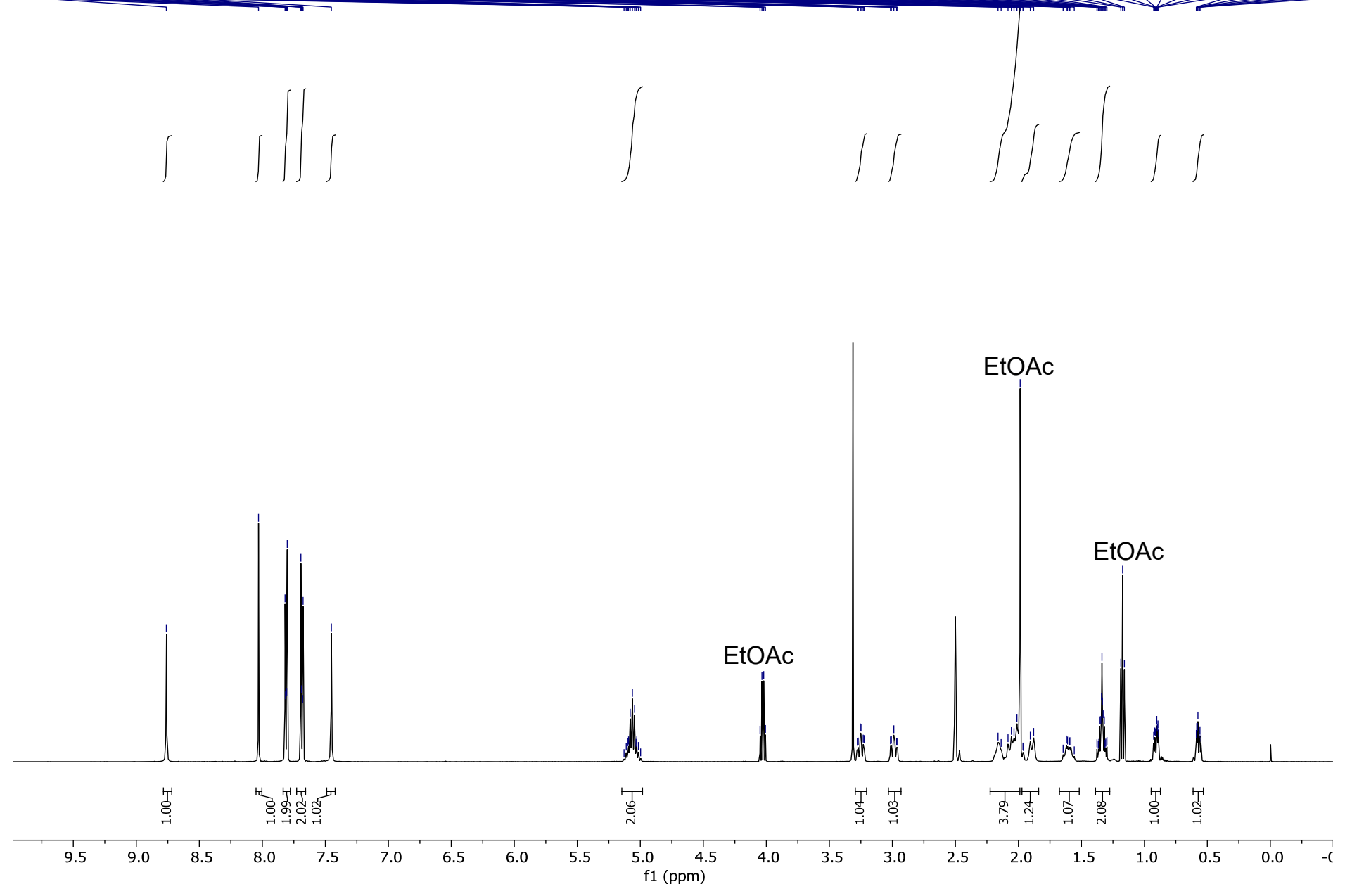
13C NMR (126 MHz, DMSO-d6)<smiles>CC(C)(C)NS(=O)(=O)c1ccc(-c2cn(CC(F)(F)F)nc2[C@@H]2CCC(F)(F)C[C@H]2C(=O)NC2(C#N)CC2)cc1</smiles>
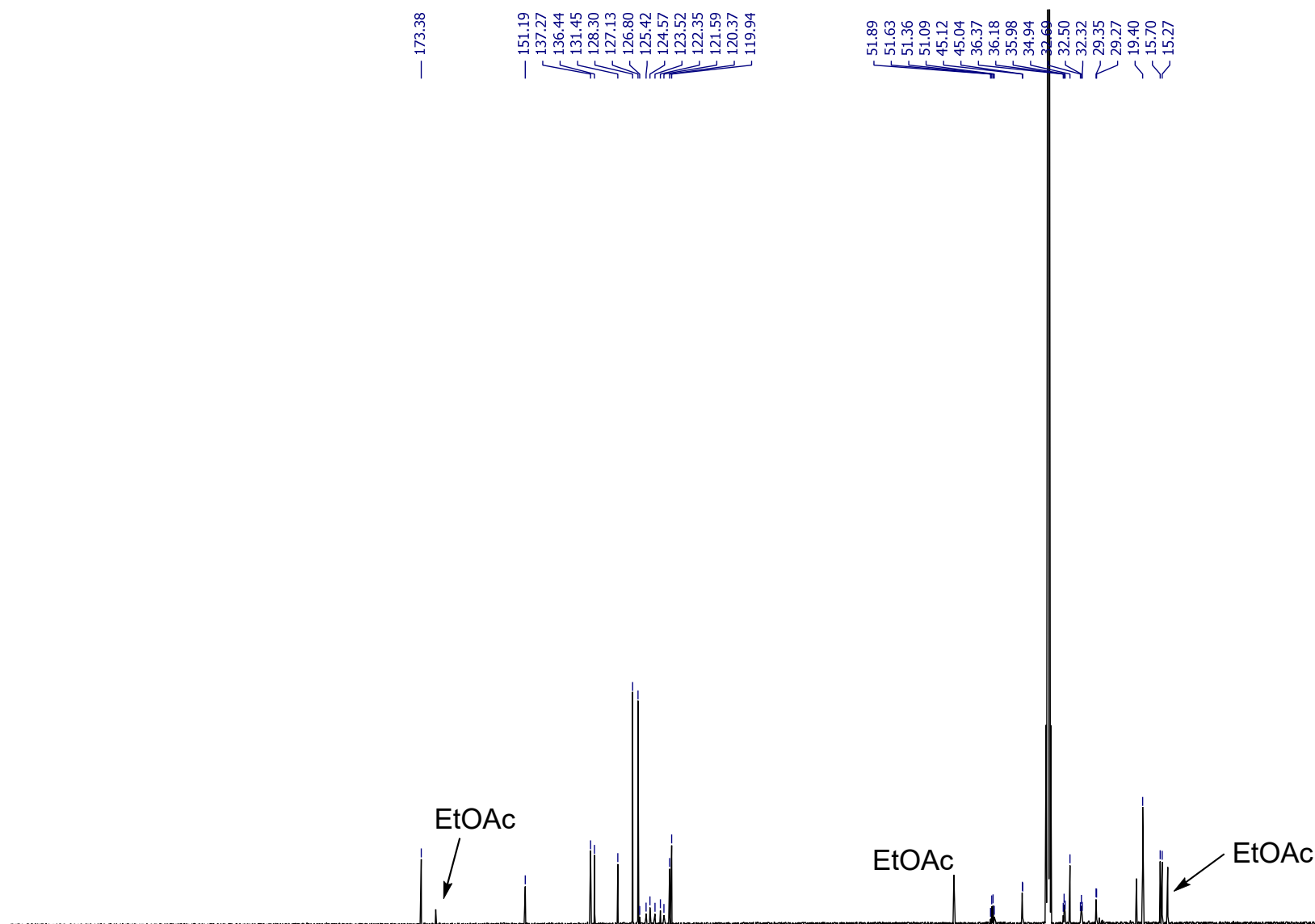

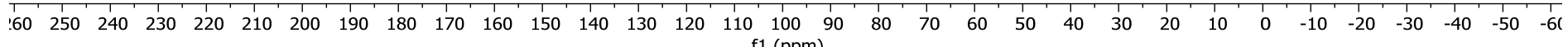


